\title{
A Review of Techniques for Diagnosing the Atmospheric Boundary Layer Height (ABLH) Using Aerosol Lidar Data
}

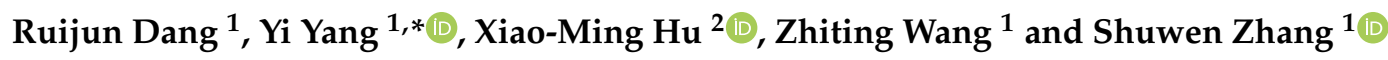 \\ 1 Key Laboratory for Semi-Arid Climate Change of the Ministry of Education, College of Atmospheric \\ Sciences, Lanzhou University, Lanzhou 730000, China \\ 2 Center for Analysis and Prediction of Storms and School of Meteorology, University of Oklahoma, Norman, \\ OK 73072, USA \\ * Correspondence: yangyi@lzu.edu.cn; Tel.: +86-138-9325-6933
}

Received: 20 May 2019; Accepted: 1 July 2019; Published: 4 July 2019

\begin{abstract}
The height of the atmospheric boundary layer (ABLH) or the mixing layer height (MLH) is a key parameter characterizing the planetary boundary layer, and the accurate estimation of that is critically important for boundary layer related studies, which include air quality forecasts and numerical weather prediction. Aerosol lidar is a powerful remote sensing instrument frequently used to retrieve the ABLH through detecting the vertical distributions of aerosol concentration. Presently available methods for ABLH determination from aerosol lidar are summarized in this review, including a lot of classical methodologies as well as some improved versions of them. Some new recently developed methods applying advanced techniques such as image edge detection, as well as some new methods based on multi-wavelength lidar systems, are also summarized. Although a lot of techniques have been proposed and have already given reasonable results in several studies, it is impossible to recommend a technique which is suitable in all atmospheric scenarios. More accurate instantaneous ABLH from robust techniques is required, which can be used to estimate or improve the boundary layer parameterization in the numerical model, or maybe possible to be assimilated into the weather and environment models to improve the simulation or forecast of weather and air quality in the future.
\end{abstract}

Keywords: aerosol lidar; atmospheric boundary layer height; gradient methods; wavelet covariance transform; ideal profile fitting; variance analysis; extended Kalman Filter

\section{Introduction}

The atmospheric boundary layer (ABL), also called the planetary boundary layer (PBL), is the turbulent layer that is directly influenced by the Earth's surface and responds to surface impact over a short period of time [1]. The substances emitted into the ABL are gradually dispersed horizontally and vertically due to the action of the turbulence, and are finally completely mixed over the layer if sufficient time is given and if there are no significant sinks [2]. Therefore, the height of mixing layer (MLH) is a key parameter for air pollution meteorology as it determines the volume available for the dispersion of pollutants; it is also a scaling parameter for the description of vertical profiles such as wind and turbulence.

A simple scheme of the diurnally varying ABL in clear-sky situation can be divided into four snapshots, the convective boundary layer (CBL) in daytime, more stable nocturnal boundary layer (NBL) at night, the early morning transition (EMT) period, and early evening transition (EET) period (Figure 1). The MLH is generally defined as the height up to which the atmospheric properties or 
substances are dispersed almost uniformly over the entire depth of the mixing layer due to turbulent vertical mixing process [1,3,4] (Figure 2). For the well-mixed CBL, aerosol particles are well mixed by the thermally driven turbulence, the MLH is more or less identical to the ABL height (ABLH) (or CBL height, $\mathrm{CBLH}$ ) shown as the left frame in Figure 2. At night, shown as the right frame in Figure 2, the nocturnal SBL can be divided into two layers, a near surface mixing layer of continuous turbulence mechanically produced and an upper layer of sporadic or intermittent turbulence, corresponding to two aerosol layers. The MLH is identical to the height of the lower stable surface layer (or ground inversion layer), the ABLH (or nocturnal boundary layer height, NBLH) is identical to the height of upper layer, a residual aerosol layer (RL) which is a remnant of the daytime CBL. The EET refers to the period from the sunset to the time when a surface stable layer is formed [5], while the EMT refers to the period from sunrise to the time when the NBL is eroded and the CBL begins to grow rapidly [6]. During EET, the convection is weakening and a ground inversion layer is generating, the strongest aerosol gradient occurs at the RL top, until new aerosol layer generated at the ground provides a renewed strong gradient. During the EMT, the production of thermal forced turbulence begins and the surface inversion layer is gradually destroyed. The strongest aerosol gradient corresponds to the top of RL or ground aerosol layer. During those periods, there is high uncertainty and inaccuracy results for the ABLH determination [5-7].

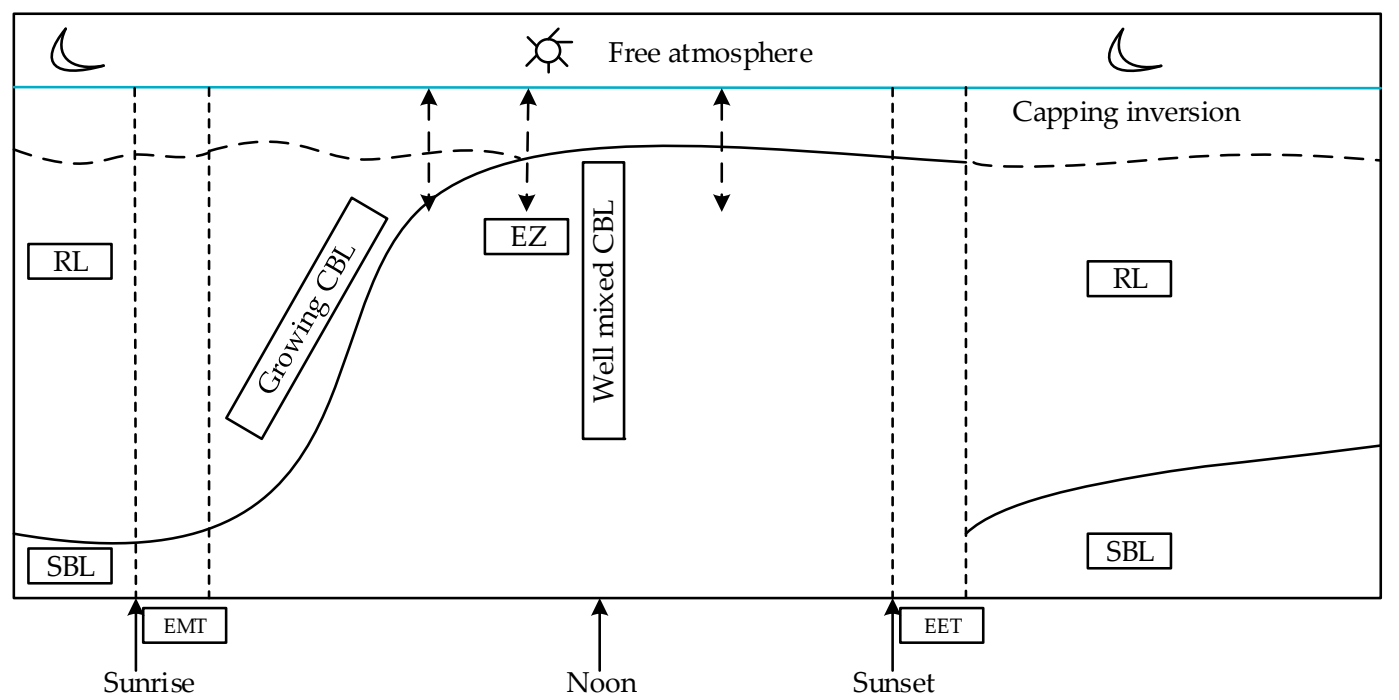

Figure 1. A simplified scheme of diurnal cycle of atmospheric boundary layer (ABL) in clear-sky situations (adapted from Stull [1]). Solid line marks the height of ABL (ABLH), the dashed line marks the top of residual layer (RL). The entrainment process near the top of ABL is marked by the dashed arrows. SBL, stable boundary layer; CBL, convective boundary layer; EZ, entrainment zone; RL, residual layer; EMT, early morning transition; EET, early evening transition.

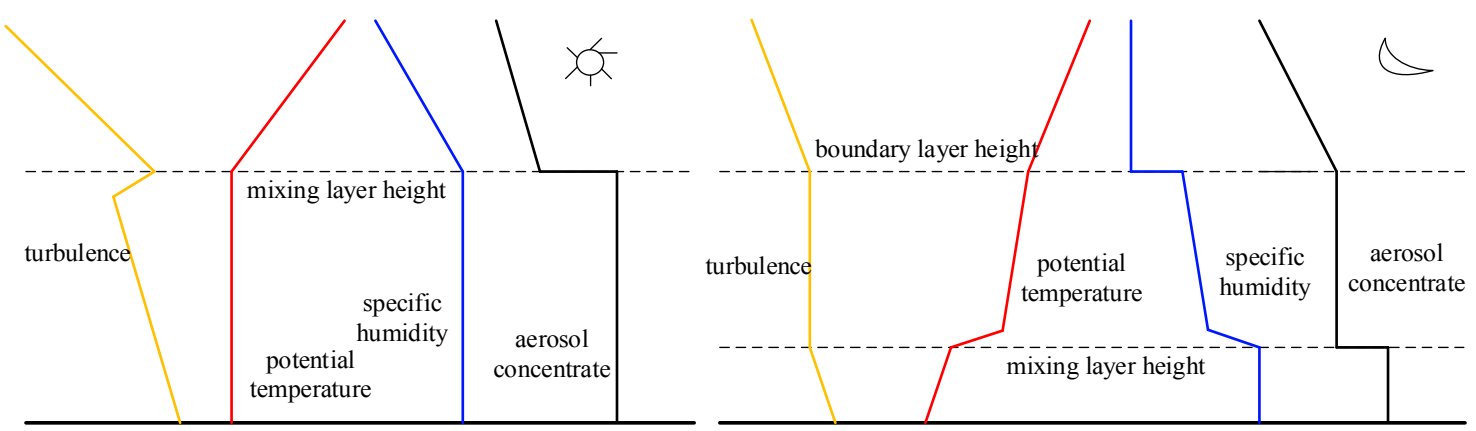

Figure 2. Principle vertical profiles of some variables for the well mixed boundary layer during daytime (left), and the more stable nocturnal boundary layer with shallow surface mixing layer, residual aerosol layer and the above free atmosphere layer (right) (adapted from Stull [1]). 
According to the definition, the ABLH or MLH can be determined from turbulent atmospheric parameters (fluxes, variances, turbulent kinetic energy, Richardson-number, structure parameters) or from suitable mean variables (potential temperature, specific humidity, mean wind, trace gas/aerosol concentrations) [8] (summarized in Table 1). The most common dataset for ABLH determination are radiosoundings (radiosonde, tethered balloon, aircraft) which are widely distributed and have a long history of use all over the world. The radiosonde measure vertical profiles of temperature, humidity, pressure, and wind speed in troposphere with high precision [9-12], but they don't directly measure turbulence. The resulting ABLH are often used as a reference for estimating the modeled results or from other instruments. In addition, the dataset are suited for studying the climatological characteristics of the ABLH [13-16]. The main disadvantages are the infrequent observation and sparse spatial coverage. Tethered balloon [17-20] and aircraft [21-23] can possibly provide turbulence and trace gas concentration profiles. ABLH estimation from profiles obtained with them are, in principle, not very different from the radiosonde-derived ABLH. However, the observations are only limited to field campaigns with manned operations, meanwhile, the high cost results in such measurements not being suitable for routine applications.

Over the past several decades, remote sensing (wind profiling radars, sodars, lidars), has been more and more introduced into ABLH studies. A fundamental advantage of remote sensing techniques is continuous operation and not causing any modification of the atmosphere being investigated. Sodar is a simpler and less expensive remote sensing system, where information on both the intensity of turbulence and the gradient of temperature and wind can be reflected from the backscatter intensity profile measurements $[24,25]$. The main shortcomings are its limited vertical detection range (a few hundred meters or up to $1 \mathrm{~km}$ ) and the reduced data availability in some special weather conditions (especially in strong convective situations without elevated temperature inversions in the afternoon) [26-29]. The wind profiling radars have been deployed at a lot of sites and have shown the success in estimating the CBLH $[30,31]$. The backscatter intensity can reflect the small-scale buoyancy fluctuations associated with the temperature and moisture fields [32,33]. For the system, the signal-to-noise ratio (SNR) is critically important, however, there are several factors including ground clutter, radio frequency interference (RFI), or atmospheric point targets such as birds [34], that can result in errors in SNR estimation which finally produce erroneous ABLH [35]. The microwave radiometer is a passive microwave remote sensing instrument, it provides brightness temperature profiles [36,37], based on which the temperature and water vapor profiles can be retrieved [38,39]. The disadvantage is that the vertical resolution of the profiles decreases with altitude, meanwhile, the retrieved vertical profiles are generally of poor quality under cloudy or rainy conditions [38]

Among the remote sensing systems, lidar is a powerful active remote sensing instrument measuring vertical profile of aerosol, wind speed, or trace gas such as water vapor. Relatively, the water vapor lidar is less convenient and more expensive, is less frequently used than aerosol lidar. The wind lidar measures wind speed and direction starting above the ground and reaching up to a height depending on the aerosol content of atmosphere [40]. Presently, using wind lidar to estimate the ABLH is less widely used than aerosol lidar but it is a promising method. The aerosol lidar-derived ABLH is actually the height of surface aerosol layer. Shown as Figure 2, for well-mixed CBL at daytime, the aerosol depth represents the MLH, ideally, the lidar-determined MLH should be equivalent to the radiosonde-derived CBLH with the assumption that the distribution of aerosol concentration is dominated by turbulent mixing. For stable NBL, the height determined by aerosol lidar is either the top of RL (NBLH) or the top of surface mechanical driven ML (MLH, or the height of ground inversion layer). During the transition (EMT and EET) periods, the altitude determined by the lidar is the altitude to which aerosol particles have been mixed in the past, rather than the altitude to which they are currently being mixed. Lidar technique shows several advantages including high temporal resolution and wide vertical spatial coverage, the instrument can possibly be operated continuously in an almost automated status. Thus, instantaneous record of ABLH allows for diurnal evolution and long-term climate studies [41-46]. At present in many countries and regions, a great number of aerosol lidars 
have been deployed and have established networks including both ground-based systems such as ACTRIS/EARLINET (Aerosols, Clouds, and Trace Gases Research Infrastructure, http://www.actris.net/, or the European Aerosol Research Lidar Network, http://www.earlinet.org/) [47,48], AD-net (the Asian dust and aerosol observation lidar network, http://www-lidar.nies.go.jp/AD-Net/) [49], and satellite-based measurements, such as CALIPSO (Cloud-Aerosol Lidar and Infrared Pathfinder Satellite Observations, https://www-calipso.larc.nasa.gov/) [50]. The lidar networks provide numerous valuable observations for boundary layer studying. Meanwhile, a lot of approaches have been proposed and developed to diagnose the ABLH from aerosol lidar observations.

Table 1. Some Measurements for ABLH (ABLH, atmospheric boundary layer height; $\mathrm{CBL}$, convective boundary layer; SNR, signal-to-noise ratio).

\begin{tabular}{|c|c|c|c|c|}
\hline Measurements & Observations & Advantages & Shortcomings & $\begin{array}{l}\text { Examples of } \\
\text { References }\end{array}$ \\
\hline \multicolumn{5}{|l|}{ Radiosoundings } \\
\hline Tethered balloons & $\begin{array}{l}\text { Turbulence } \\
\text { Trace gas } \\
\text { concentration }\end{array}$ & $\begin{array}{l}\text { turbulence } \\
\text { measurements possible } \\
\text { the ascent velocity can be } \\
\text { controlled according to } \\
\text { the desired resolution }\end{array}$ & $\begin{array}{ll}\text { - } & \text { high cost } \\
\text { - } & \text { limited to field } \\
\text { campaigns with } \\
\text { manned operation } \\
\text { - } \quad \text { limited } \\
\text { measurement range } \\
\text { inapplicable in case of } \\
\text { high wind speed or } \\
\text { strong convection }\end{array}$ & $\begin{array}{l}\text { Moores et al. (1979) } \\
\text { Vernekar et al. (1991) } \\
\text { Holden et al. (2000) }\end{array}$ \\
\hline Aircraft & $\begin{array}{l}\text { Turbulence } \\
\text { Temperature } \\
\text { Humidity } \\
\text { Wind }\end{array}$ & $\begin{array}{l}\text { - } \quad \begin{array}{l}\text { simultaneous } \\
\text { measurements of mean } \\
\text { and turbulent quantities }\end{array} \\
\text { - } \quad \text { high sampling rate }\end{array}$ & $\begin{array}{l}\text { - } \\
\text { high cost } \\
\text { limited to } \\
\text { field campaigns } \\
\text { the lowest observation } \\
\text { height (or flight level) is } \\
\text { restricted (security) }\end{array}$ & $\begin{array}{l}\text { Galmarini and Attié } \\
(2000) \\
\text { Dai et al. (2011) } \\
\text { Dai et al. (2014) }\end{array}$ \\
\hline $\begin{array}{l}\text { Microwave } \\
\text { radiometer }\end{array}$ & $\begin{array}{l}\text { Brightness } \\
\text { temperature }\end{array}$ & $\begin{array}{l}\text { providing good estimate } \\
\text { of temperature and } \\
\text { humidity in the lower } \\
\text { troposphere with high } \\
\text { temporal resolution }\end{array}$ & $\begin{array}{l}\text { - the vertical resolution } \\
\text { decreases with altitude } \\
\text { poor data quality in } \\
\text { cloudy and } \\
\text { rainy conditions }\end{array}$ & $\begin{array}{l}\text { Crewell et al. (2007) } \\
\text { Cimini et al. (2013) } \\
\text { Saeed et al. (2015) } \\
\text { Liu et al. (2015) }\end{array}$ \\
\hline
\end{tabular}


Table 1. Cont.

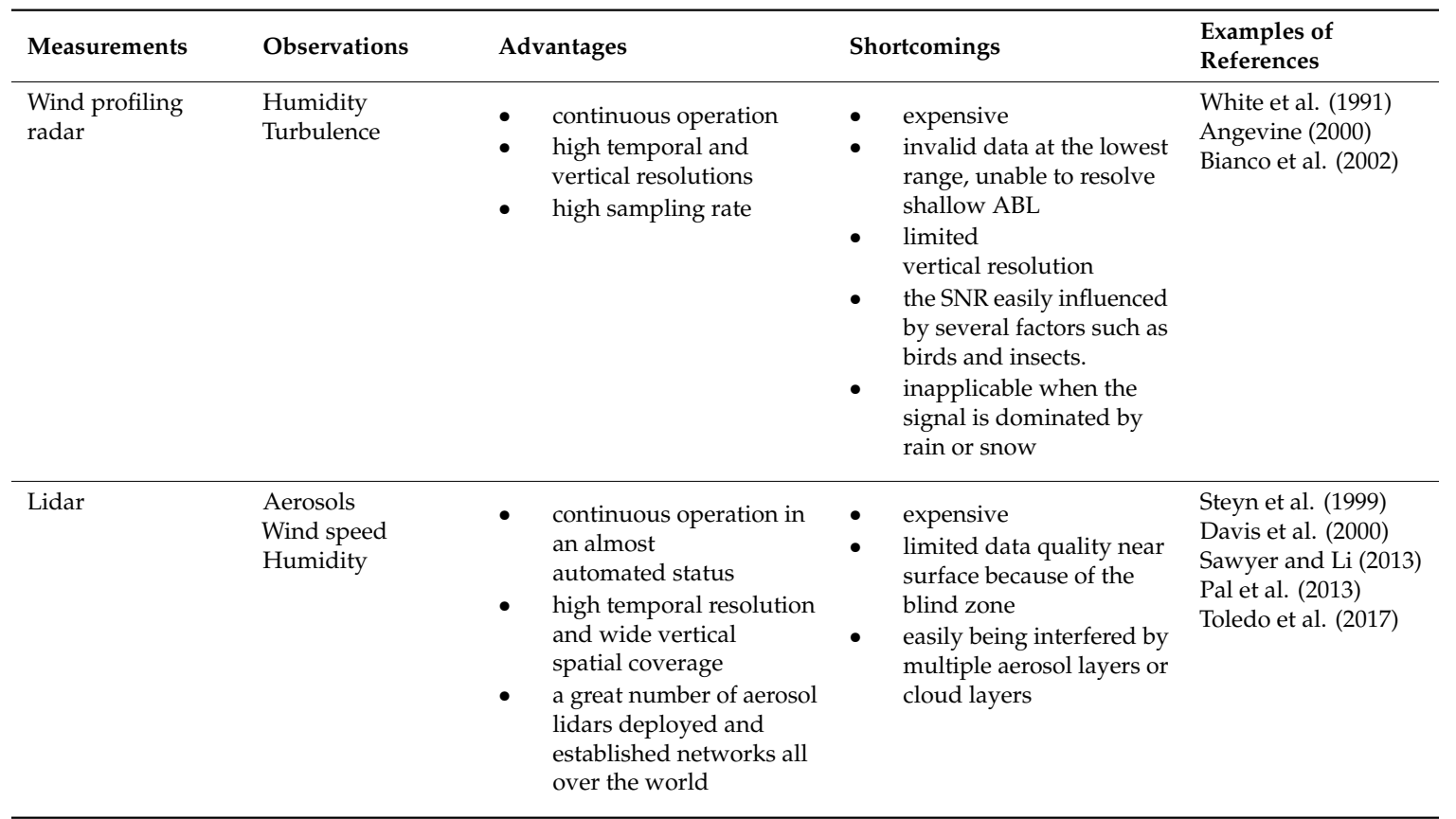

Seibert [2] has given an overview on methods to determine the MLH from in-situ measurements and surface-based remote sensing. Since then, several lidar systems have been built and a great development about lidar observation has taken place. Emeis et al. [51] summarized some most basic optical detection methods and gave a review focusing on the rapid development of surface-based remote sensing of the MLH with a main topic of MLH determination from ceilometer since the year 2000. Ceilometer can be regarded as a small lidar while it has a lower range gate than lidar. In recent years, several classical methodologies have been improved, meanwhile, some new ideas or algorithms have been proposed and developed by incorporating some advanced techniques such as image edge detection [52], cluster analysis [53], and layer tracking [54], etc.

This paper gives a new review of presently available methods for the aerosol lidar measurements of ABLH or MLH with some real cases based on the MPL profiles over SACOL (Semi-Arid Climate Observatory and Laboratory) in China. The SACOL $\left(35.57^{\circ} \mathrm{N}, 104.08^{\circ} \mathrm{E} ; 1965.8 \mathrm{~m}\right.$ above sea level) is located at the top of Tsuiying Mountain in the Yuzhong campus of Lanzhou University. The reference ABLH is defined by the theta-gradient method (the altitude where the maximum of the theta gradient occurs $[42,55]$ ) based on the potential temperature profiles provided by a nearby radiosonde site $\left(35.87^{\circ} \mathrm{N}, 104.15^{\circ} \mathrm{E} ; 1875 \mathrm{~m}\right.$ above sea level $(90.8 \mathrm{~m}$ lower than SACOL)), which is approximately $8.83 \mathrm{~km}$ from SACOL (detail descriptions about lidar system over SACOL, and the radiosonde-provided profiles of atmospheric variables see Dang et al. [56]). The methodologies include several traditional algorithms, some improved versions of them, as well as some new aspects developed in recent years, which are introduced in Section 2, Section 3, and Section 4. Section 5 presents summary and conclusions with brief discussion and prospect.

\section{Classical Methodologies for Lidar Measurement of ABLH}

The lidar technique employs light emitted by a laser source to sound the atmosphere with high temporal and vertical resolutions through collecting and detecting the light backscattered by the atmosphere [57,58]. A detailed description about the measurement can be found, for example, by Measures [59]. Welton and Campbell [60] discussed the uncertainties and the factors that affect the MPL measured data. The raw lidar data are corrected in terms of dead-time, afterpulsing, background, 
overlap, and pulse energy, the detail procedures were depicted elaborately by Campbell et al. [61] and Kotthaus et al. [62]. The single-backscattering lidar equation can be expressed as:

$$
\begin{gathered}
R S(Z)=\frac{C}{Z^{2}} \beta(Z) \exp \left[-2 \int_{0}^{Z} \alpha\left(Z^{\prime}\right) d Z^{\prime}\right] \\
R S C S(Z)=R S(Z) Z^{2}=C \beta(Z) \exp \left[-2 \int_{0}^{Z} \alpha\left(Z^{\prime}\right) d Z^{\prime}\right]
\end{gathered}
$$

where $C$ is a constant for a given lidar system, $\beta(z)$ and $\alpha(z)$ represent the total backscatter coefficient (sum of molecular and particulate contributions, $\beta(z)=\beta(m)+\beta(p)$ ) and total extinction coefficient $(\alpha(z)=\alpha(m)+\alpha(p)), \mathrm{Z}$ is the range to the target, respectively. Equation (2) presents the range-corrected signal (RSCS). Previous studies on CBL by backscattering lidar are mostly based on the analysis of RSCS, which is sufficient for determining CBLH or for qualitative research on CBL structure. When lidar data are used, the blind zone caused by the overlap between the lidar laser beam and its receiver field of view has to be taken into consideration, the application of the data in the zone (a few hundred meters) is limited.

In the following subsection, several classical methodologies for ABLH determination depending on lidar backscatter intensity or RSCS profiles will be summarized (Table 2). The known methods are mostly based on two assumptions: Firstly, the ABL is more polluted than the upper free atmosphere (FT) [63], the aerosol concentration difference between ABL and FT results in a strong negative gradient of lidar backscatter signal [64]; secondly, the entrainment process occurs at the top of well-mixed CBL, which entrains the clear air masses from FT into CBL leading to locally considerable fluctuations in the aerosol concentration which presents as significant temporal variations (variance) in lidar signal [65]. Therefore, for CBL, assuming that the vertical aerosol distribution rapidly adapts to the changes in the thermal structure of the boundary layer, the MLH (or CBLH) can be determined; for NBL, the determined height is either the depth of RL (NBLH) or the top of surface aerosol layer (MLH). Classical methodologies include: (1) visual inspection, (2) the threshold method, (3) the gradient methods, (4) the ideal profile fitting (or curve fitting) (FIT), (5) the wavelet covariance transform (WCT), and (6) the variance (or standard deviation) analysis (VAR or STD). In comparison, the signal-gradient-based methods yield instantaneous ABLH with the temporal resolution of the observation system whereas the variance analysis yields the mean CBLH over about one hour (according to the definition of ABL by Stull [1]).

\subsection{Visual Inspection (or Ocular Estimate)}

The visual inspection, a subjective analysis method, can be applied to various profiles such as temperature, wind, humidity, Richardson-number, and aerosol concentrations [66-68]. The ABLH can be ocular estimated based on the significant transition of aerosol concentration between the ABL and upper FT $[69,70]$. For this simplest method, the visual error is unavoidable, and the results contain significant subjectivity. The method can only be used to roughly estimate the ABLH and can't be automatically operated, thus makes necessary the objective analysis method. 
Table 2. Classical lidar-based methodologies to derive ABLH (RL, residual layer)

\begin{tabular}{|c|c|c|c|}
\hline Methods & Advantages & Shortcomings & Examples of References \\
\hline $\begin{array}{l}\text { Visual inspection } \\
\text { (Ocular estimate) }\end{array}$ & - $\quad$ simple & $\begin{array}{ll}\text { - } & \text { subjective } \\
\text { - } & \text { visual error } \\
\text { inability to process large } \\
\text { volumes of lidar data } \\
\text { automatically } \\
\text { or efficiently }\end{array}$ & Flamant et al. (1997) \\
\hline Threshold method & $\begin{array}{ll}\text { - } & \text { simple } \\
\text { - } & \text { less subjective than } \\
\text { ocular estimate }\end{array}$ & $\begin{array}{l}\text { - } \quad \text { difficult to define an } \\
\text { appropriate and } \\
\text { universal threshold } \\
\text { - } \quad \text { interfered by multiple } \\
\text { layers such as cloud layer } \\
\text { and RL } \\
\text { - } \quad \text { require subjective check }\end{array}$ & $\begin{array}{l}\text { Melfi et al. (1985) } \\
\text { Dupont et al. (1994) } \\
\text { Frioud et al. (2003) }\end{array}$ \\
\hline $\begin{array}{l}\text { Gradient methods: } \\
\text { - } \quad \text { First-order gradient } \\
\text { - } \quad \text { inflection } \\
\text { - } \quad \text { point(second derivative) } \\
\text { - } \quad \text { cubarithm gradient } \\
\end{array}$ & $\begin{array}{ll}\text { - } & \text { objective } \\
\text { - } & \text { low computation cost }\end{array}$ & $\begin{array}{l}\text { - } \quad \text { sensitive to noisy data } \\
\text { interfered by multiple } \\
\text { layers such as cloud layer } \\
\text { and RL } \\
\text { averaging may be } \\
\text { required to improve } \\
\text { signal-to-noise ratio }\end{array}$ & $\begin{array}{l}\text { Hayden et al. (1997) } \\
\text { Sicard et al. (2006) } \\
\text { Menut et al. (1999) } \\
\text { Senff et al. (1996) }\end{array}$ \\
\hline $\begin{array}{l}\text { Ideal profile fitting } \\
\text { (curve fitting) }\end{array}$ & $\begin{array}{l}\text { using the entire } \\
\text { vertical } \\
\text { backscatter profile } \\
\text { - less sensitive to signal } \\
\text { local structures }\end{array}$ & $\begin{array}{l}\text { - not suitable in cases of } \\
\text { clean, near-surface air } \\
\text { overlain by aerosol } \\
\text { laden air } \\
\text { relatively } \\
\text { rich computation }\end{array}$ & $\begin{array}{l}\text { Steyn et al. (1999) } \\
\text { Eresmaa et al. (2005) }\end{array}$ \\
\hline $\begin{array}{l}\text { Wavelet covariance } \\
\text { transform }\end{array}$ & $\begin{array}{l}\text { - } \quad \text { requires little prior } \\
\text { information about the } \\
\text { atmosphere or } \\
\text { the lidar } \\
\text { - } \quad \text { automated detection }\end{array}$ & $\begin{array}{l}\text { - } \quad \text { interfered by multiple } \\
\text { layers such as cloud layer } \\
\text { and RL } \\
\text { an appropriate dilation of } \\
\text { the wavelet is critical }\end{array}$ & $\begin{array}{l}\text { Mallat et al. (1992) } \\
\text { Gamage and Hagelberg } \\
\text { (1993) } \\
\text { Brooks et al. (2003) } \\
\text { Cohn and Angevine } \\
\text { (2000) } \\
\text { Davis et al. (2000) } \\
\text { Morille et al. (2007) } \\
\text { Moreira et al. (2014) }\end{array}$ \\
\hline $\begin{array}{l}\text { Variance (or Standard } \\
\text { Deviation) analysis }\end{array}$ & $\begin{array}{l}\text { - less sensitive to } \\
\text { transient signal noise }\end{array}$ & $\begin{array}{ll}\text { - } & \text { sensitive to number of } \\
\text { profiles for } \\
\text { variance calculating } \\
\text { - } & \text { only suitable for } \\
\text { daytime CBL } \\
\text { - } \quad \text { resulted ABLH with } \\
\text { lower } \\
\text { temporal resolution }\end{array}$ & $\begin{array}{l}\text { Piironen and Eloranta } \\
\text { (1995) } \\
\text { Menut et al. (1999) }\end{array}$ \\
\hline
\end{tabular}

\subsection{Thereshold Method}

The threshold method generally defines the ABLH as the altitude where the backscatter intensity or the intensity gradient exceeds a preset threshold [71,72]. Melfi et al. [63] and Boers et al. [73] defined the CBLH as the height within the vertical profile of the backscatter intensity where the intensity first exceeds a small fixed threshold (e.g., $25 \%$ ) when coming downward from the unpolluted FT. Frioud et al. [74] used a threshold of $4 \times 10^{-4} \mathrm{~m}^{-1}$ for intensity gradient to distinguish the gradient small-peaks minima due to small drop in ML from oscillations due to noise. The threshold method suffers from the need to define the thresholds appropriately, it easily results in a subjective analysis of ABLH. 


\subsection{Gradient Method (GMs)}

The derivative of RSCS exhibits a strong negative peak marking the transition between the ML and FT [75]. Hayden et al. [76] and Flamant [69] first used the first-order gradient method (GM) to determine the CBLH based on the lidar backscatter intensity. GM defines the ABLH as the position of largest negative peak of the first derivative of RSCS [77]:

$$
H_{G M}=H \mid \min \left(\frac{\partial(R S C S)}{\partial r}\right)
$$

Similarly, the second-order derivative method known as the inflection point method (IPM) [78], as well as the logarithm gradient method (LGM) $[79,80]$ were proposed, which determine the ABLH through looking for the absolute minimum value of the second-order derivative or the gradient of the logarithm of RSCS with respect to the altitude:

$$
\begin{gathered}
H_{I P M}=H \mid \min \left(\frac{\partial^{2}(R S C S)}{\partial r^{2}}\right) \\
H_{L G M}=H \mid \min \left(\frac{\partial \ln (R S C S)}{\partial r}\right)
\end{gathered}
$$

Recently, Yang et al. [81] took the impact of the gravity waves on vertical aerosol distribution into consideration and proposed the cubic root gradient method (CRGM), which defines the ABLH as the height where the minimum of the cubic root gradient of the RSCS occurs [82]:

$$
H_{C R G M}=H \mid \min \left(\frac{\partial(R S C S)^{1 / 3}}{\partial r}\right)
$$

An example RSCS profile is observed by the MPL over SACOL at 12:00 UTC on 10 September 2010. The potential temperature and the specific humidity profiles at the same time are provided by a nearby radiosonde site. Figure 3a shows the RSCS profile, the profiles of the first-, second-order, logarithm and the cubic root gradient of RSCS with the respectively determined ABLH named as $h(G M), h(I P M)$, $\mathrm{h}(\mathrm{LGM}), \mathrm{h}(\mathrm{CRGM})$. In this clear-sky case with simple RSCS profile, the gradient-methods-determined ABLH are $0.095 \mathrm{~km}, 0.036 \mathrm{~km}, 0.186 \mathrm{~km}$, and $0.186 \mathrm{~km}$ higher than the theta-gradient-determined thermodynamic CBLH, respectively ( $\mathrm{h}(\mathrm{PT})$ in Figure $3 \mathrm{~b}$ ). Among four gradient-based algorithms, the difference between IPM-determined and radiosonde-derived ABLH is smallest, which is a common conclusion [83].

The gradient-based methods are easy to operate and retrieve the ABLH with small computation cost when the characteristics of the ABL is clear. However, the methods perform poor when there are several local minimums in signal gradient profile caused by cloud layers, multiple aerosol layer, or signal noise [43,84]. To eliminate the noise effect and improve SNR, vertical and temporal averaging is often necessary, which possibly leads to lose some instantaneous useful information as well as introduce some additional uncertainties. Although less subjective than the threshold method, the gradient-based methods are somewhat arbitrary anyway especially the GM. When they are applied, validation by that determined from other data types or methods are required for estimation. 

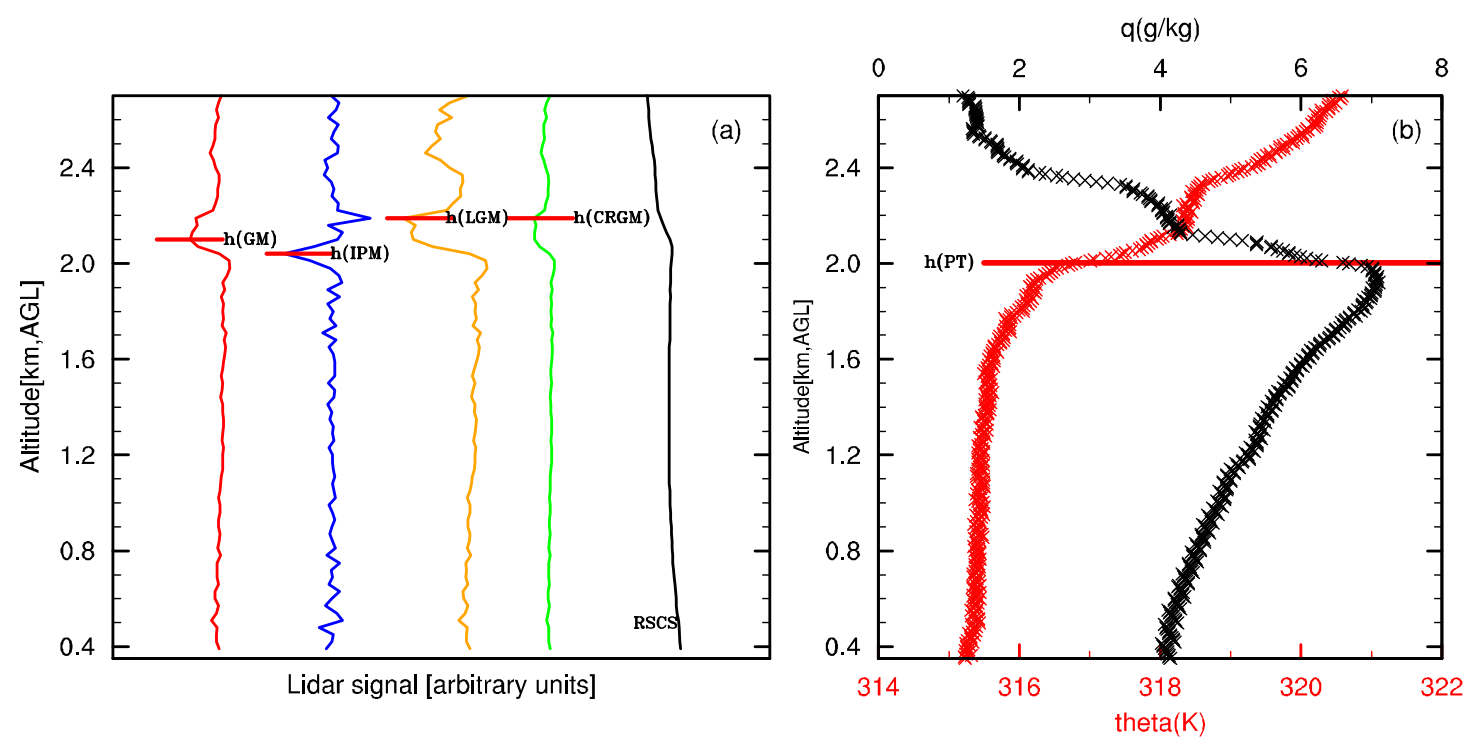

Figure 3. A case at 12:00 UTC on 10 September 2010 over SACOL (Semi-Arid Climate Observatory and Laboratory, in China). (a) the profiles of lidar range-squared-corrected signal (RSCS, black solid line), first derivative (red solid line), second derivative (blue solid line), the logarithm gradient (orange solid line) and the cubic root gradient (green solid line) of RSCS provided by a micro-pulse lidar (MPL), the respectively determined ABLH are named as $\mathrm{h}(\mathrm{GM}), \mathrm{h}(\mathrm{IPM}), \mathrm{h}(\mathrm{LGM}), \mathrm{h}(\mathrm{CRGM}),(\mathbf{b})$ the profiles of potential temperature (red profile) and the specific humidity (black profile) at a nearby radiosonde site with the CBLH determined by the theta-gradient method (h(PT)).

\subsection{Ideal Profile Fitting (Curve Fitting) (FIT)}

Steyn et al. [85] first proposed the ideal profile fitting also known as curve fitting (FIT) method which was later developed by Eresmaa et al. [86]. The technique is an extension of the gradient method, the ABLH is derived from fitting an idealized ABL backscatter profile $(B(z)$, Equation $(7))$ to the lidar observed signal profile $(b(z))$ by minimizing the difference between the two profiles $[87,88]$. The $B(z)$ represents the possibly simplest signal profile, with high backscatter values in the ML and lower backscatter signal in air overlying the ML, and a sharp transition between them shown as Figure 4a. It is defined as

$$
B(z)=\frac{\left(B_{m}+B_{u}\right)}{2}-\frac{\left(B_{m}-B_{u}\right)}{2} \operatorname{erf}\left(\frac{z-z_{m}}{s}\right)
$$

where the error function $(e r f)$ is defined as:

$$
\operatorname{erf}(a)=\frac{2}{\sqrt{\pi}} \int_{0}^{a} \exp \left(-z^{2}\right) d z
$$

where $B_{m}$ and $B_{u}$ are the mean backscatter in the ML and in the air immediately above the ML, $S$ is related to the thickness of entrainment zone (EZT). Steyn et al. [85] defined EZT $=2.77 \mathrm{~s}$ as the so-called entrainment zone, the layer in which the mixing ratio of ML and overlying air lies in the range 0.05-0.95. Two new constants $A_{1}$ and $A_{2}$ were defined by Eresmaa et al. [86], $A_{1}=\left(B_{m}+B_{u}\right) / 2$, $A_{2}=\left(B_{m}-B_{u}\right) / 2$. Thus, the quality of fitting is strongly dependent on the estimation of the $A_{1}$ based on the initial order-of-magnitude guess for the ABLH. The fitting process for the case in Figure 3 is shown as Figure $4 \mathrm{~b}$. The small difference between the FIT-determined ABLH and the theta-gradient-determined CBLH is $0.004 \mathrm{~km}$. The robustness of the technique is based on utilizing the whole backscatter profile rather than the profile surrounding the top of ML [51]. Relatively, the FIT is less sensitivity to local signal structures than the methods directly based on the gradient $[55,56]$. However, the method is more suitable when ABL with structures that match the particular idealized 
profile. In addition, the technique is not able to detect ABLH in cases of clean, near-surface air overlain by aerosol laden air.
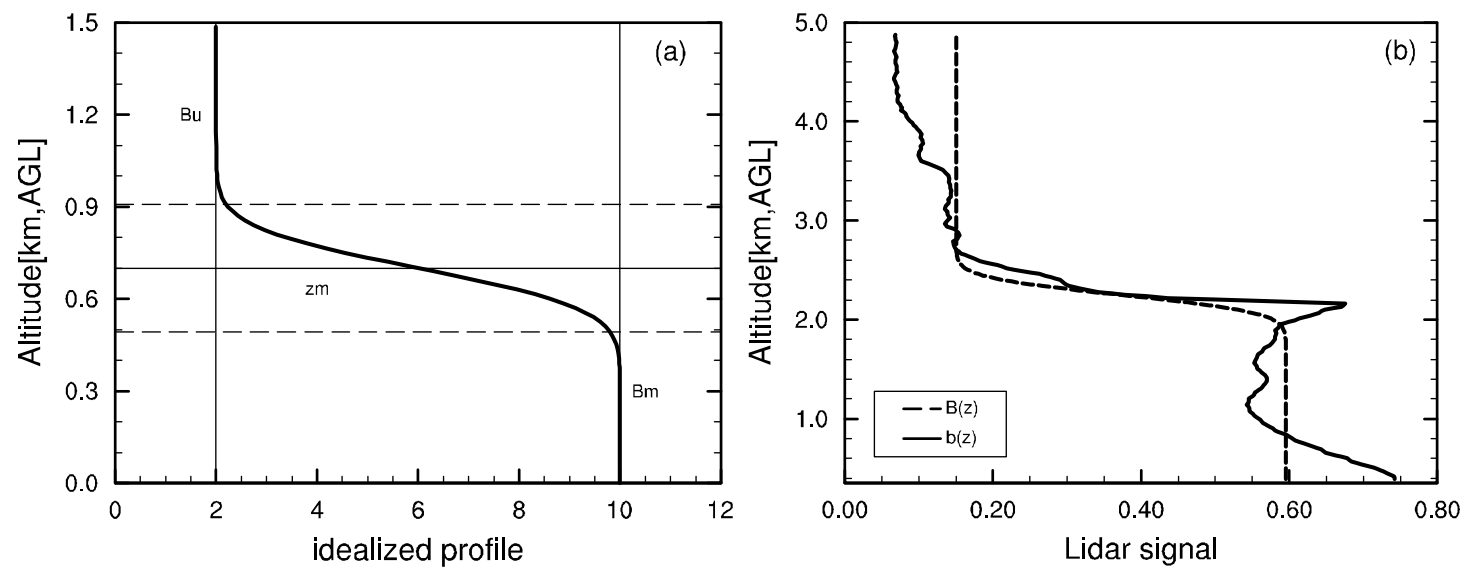

Figure 4. (a) An idealized ABL backscatter profile, (b) the curve fitting procedure for a case at 12:00 UTC on 10 September 2010 over SACOL (the same case in Figure 3; adapted from the Figure 2 in Dang et al. [56]).

\subsection{Wavelet Covariance Transform (WCT)}

Another gradient-based algorithm is called wavelet covariance transform (WCT). The method first inspired by Mallat et al. [89] has been applied to retrieve ABLH from lidar observation in many recent studies [90-96]. The ABLH is defined through calculating the similarity represented by covariance transform between the backscatter signal profile and a wavelet profile. The Haar wavelet (HAAR) [97] and the Mexican Hat wavelet (MHAT) [98,99], the shapes of which are similar to the lidar signal backscattered by aerosol layers (Figure 5a, a case at 06:00 UTC on 10 September 2010 over SACOL), have been frequently used for detecting step changes in lidar RSCS profile. Different wavelets possibly produce analysis divergence and result in discrepant ABLH [100,101].

The step, or HAAR wavelet $h$ and the covariance transform $w_{f}$ are defined by Equations (9) and (10) [93]. $z$ is the altitude, $b$ and $a$ are the translation and dilation of the wavelet, which adjust the location and shape of the wavelet. $z_{t}$ and $z_{b}$ represent the top and bottom altitudes in the RSCS profile $(X(z))$. When $h$ encounters a sharp drop in $X(z)$ (through changes in $b$ ), a local maximum in $w_{f}(a, b)$ occurs, indicating a step change in $X(z)$ located at $b$ with a coherent scale of $a$. For an appropriate $a$, the ABLH is defined as the location of $b$ where the $w_{f}(a, b)$ reaches its maximum (Figure $5 b$ ).

$$
\begin{gathered}
h\left(\frac{z-b}{a}\right)=\left\{\begin{array}{cr}
+1: & b-\frac{a}{2} \leq z \leq b \\
-1: & b \leq z \leq z+\frac{a}{2} \\
0: & \text { elsewhere }
\end{array}\right\} \\
w_{f}(a, b)=\frac{1}{a} \int_{z_{t}}^{z_{b}} X(z) h\left(\frac{z-b}{a}\right) d z
\end{gathered}
$$

The MHAT is defined as the second-order derivative of a Gaussian function $[98,99]$. The wavelet $g$ and the covariance transform $w_{f}(a, b)$ are defined by Equations (11) and (12) [102]. The covariance transform filters the RSCS gradient profile $f(z)$ with the wavelet at each translation $b$ and dilation $a$. The $w_{f}(a, b)$ changes with significant negative slope when $g$ meets a sharp decrease in $f(z)$ (Figure $5 c$ ). For an appropriate $a$, the ABLH is defined as the value of $b$ which maximizes the negative $w_{f}(a, b)$ shown as Figure 5c.

$$
g\left(\frac{z-b}{a}\right)=\left[1-\left(\frac{z-b}{a}\right)^{2}\right] \exp \left[-\frac{1}{2}\left(\frac{z-b}{a}\right)^{2}\right]
$$




$$
w_{f}(a, b)=\frac{1}{\sqrt{a}} \int_{z_{b}}^{z_{t}} f(z) g\left(\frac{z-b}{a}\right) d z
$$
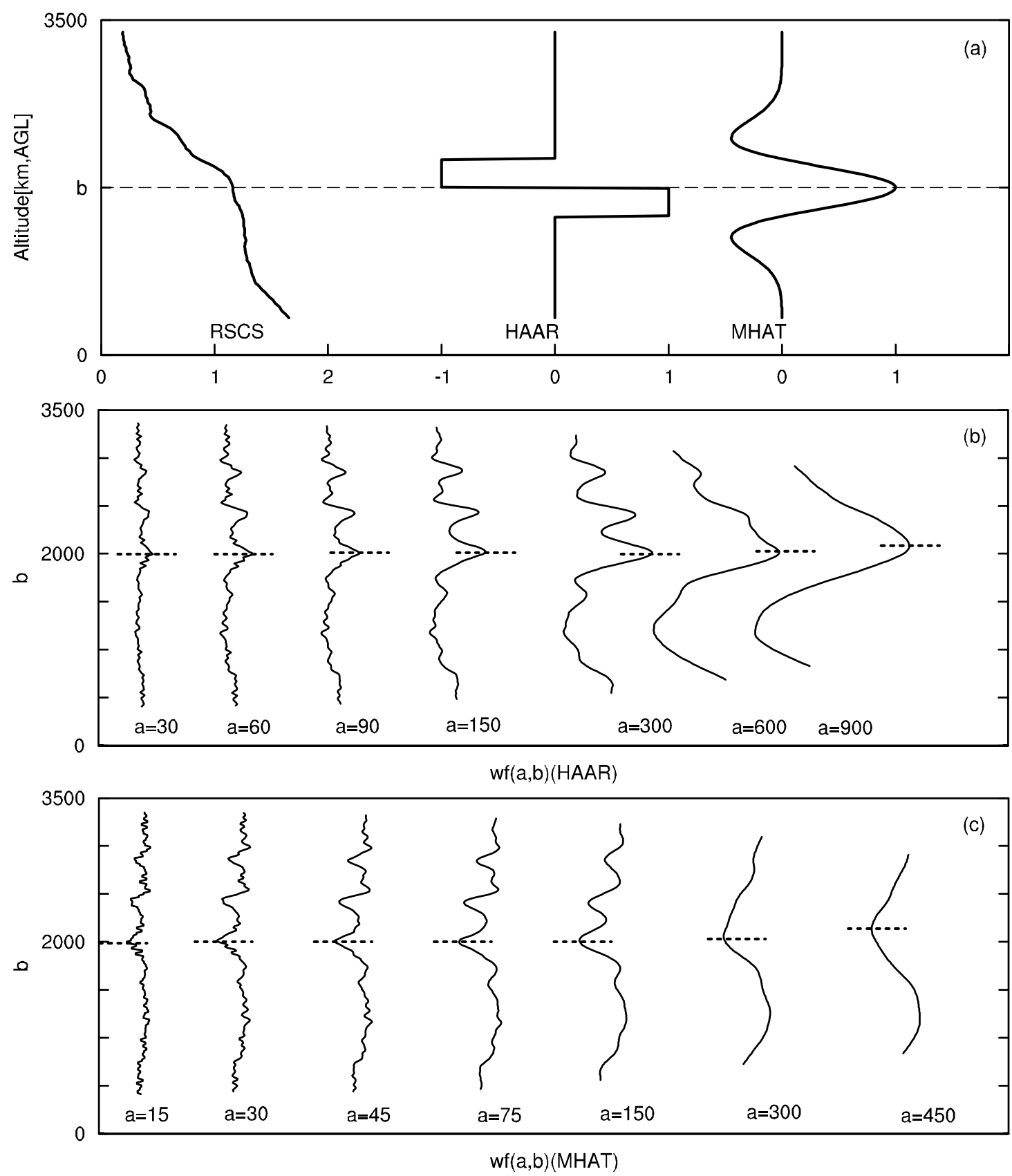

Figure 5. (a) RSCS profile with the shapes of HAAR wavelet (HAAR) and the Mexican-Hat wavelet (MHAT), the resulting covariance transform for (b) HAAR and (c) MHAT at various values of the dilation at 06:00 UTC on 10 September 2010 over SACOL.

The selection of an appropriate $a$ is the key for WCT. For a simple signal profile (the mean backscatter is near constant in both ML and the FT, and there is distinct transition zone between them), the choice of $a$ is not critical and it can be valued large enough [91]. However, in complex situations where there are several significant variations in signal profile, if $a$ is too small, the covariance transform identifies local structures in signal, while $a$ is too large, only the biggest structures are identified and adjacent signal structures may cause interference, as shown in Figure 5b,c. Davis et al. [91] indicated that, if there is significant backscatter gradient above the $\mathrm{ABL}$, the location of the maximum in 
$w_{f}(a, b)$ (Equation (10)) rises with the dilatation increase. Brooks [93] indicated that the dilation should equal to the transition zone range of the ideal profile. Granados-Muñoz et al. [96] tested the dilation parameter by an iterative procedure changing from $0.05 \mathrm{~km}$ with the steps of $0.005 \mathrm{~km}$. Gamage and Hagelberg [97] determined the optimum $a$ through defining the wavelet variance $D^{2}(a)$ (Equation (13)), which is similar to a power spectrum representing the distribution of $w_{f}(a, b)$ with $a$. The maximum in the wavelet variance occurs at the maximum possible dilation shown in Figure 6.

$$
D^{2}(a)=\int_{z_{b}}^{z_{t}}\left[w_{f}(a, b)\right]^{2} d b
$$
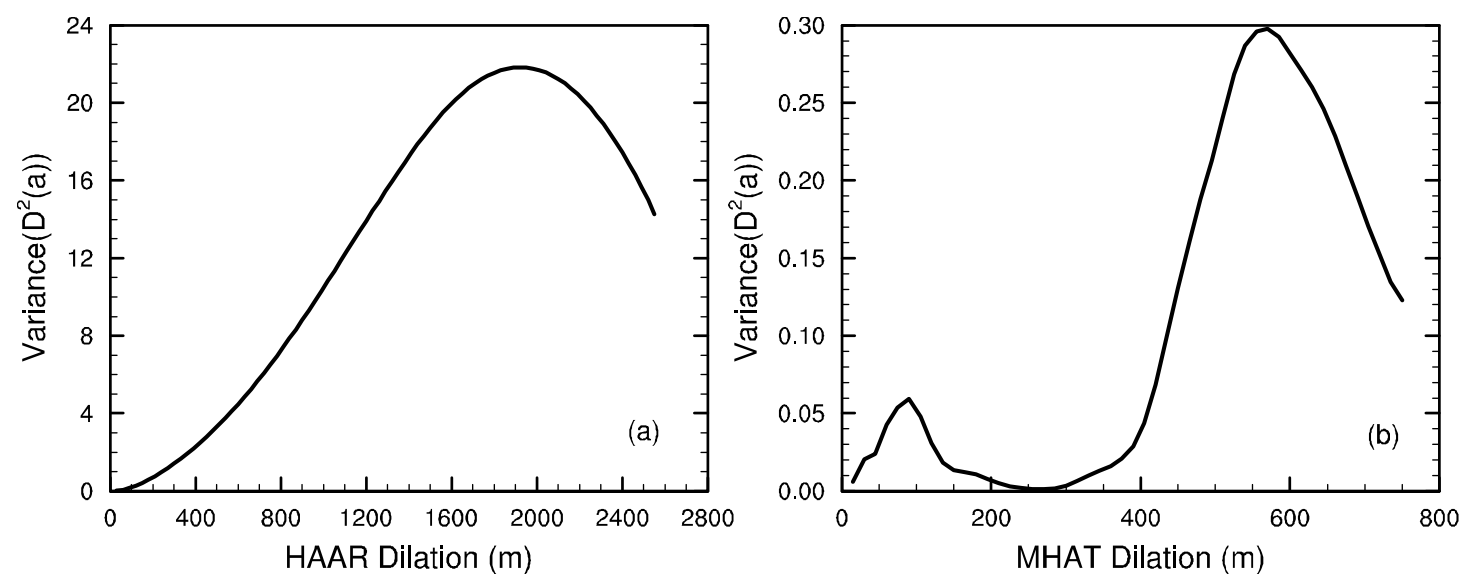

Figure 6. The wavelet variance, $D^{2}(a)$, of HAAR (a) and MHAT (b) as described in Equation (13), for the RSCS profile in Figure 5.

For the case in Figure 3 (12:00 UTC on 10 September 2010 over SACOL), when the dilation $a$ is selected as $300 \mathrm{~m}$, the HAAR-determined (or MHAT-determined) ABLH is $0.201 \mathrm{~km}$ (or $0.287 \mathrm{~km}$ ) higher than the theta-gradient-determined CBLH (Figure is not shown). For this case, the difference between lidar-defined ABLH by gradient methods, FIT and WCT are within $0.3 \mathrm{~km}$. Meanwhile, the ABLH determined by all above lidar-based algorithms are a little higher than the radiosonde-derived ABLH. This is actually a reasonable phenomenon [103]. The most energetic convective plumes could penetrate into the stable or inversion layer above the $\mathrm{ML}$, which thereby transport aerosols up to levels higher than the bottom of the stable or inversion layer. The WCT requires little prior information about the atmosphere or the lidar system which makes the method useful for ABLH automated detection $[104,105]$. However, there are also some problems. Although the HAAR can be used to find step changes in lidar signal, the dilation of the wavelet provides little information on the vertical scale of the gradient in backscatter signal, the resulted ABLH is not stable enough [90]. Furthermore, the technique is also easily interfered with by multiple layers similar to other gradient-based methods [106].

\subsection{Variance (or Standard Deviation) Analysis (VAR or STD)}

With the assumption that the entrainment process entrains dry and clear air from the FT into the ML resulting the considerable temporal fluctuations in aerosol concentration near the top of ML, the variance (VAR in Equation (14)) or standard deviation (STD in Equation (15)) analyzes the vertical profile of the temporal variations of RSCS profile during a certain time window (generally about half hour) [107]. VAR (or STD) reflects the temporal fluctuation in aerosol concentrations. The ABLH is defined as the height where the maximum variance or standard deviation of RSCS occurs $[78,108]$ shown as Figure 7. The VAR method is also easily interfered by data noise and local aerosol distribution. The total number of profiles $(N)$ for calculating the $\operatorname{VAR}(z)$ (or $\operatorname{STD}(z)$ ) within the selected time window 
will also affect the result. The applicability of the method is probably limited to well-developed CBL due to the assumptions.

$$
\begin{gathered}
\operatorname{VAR}(z)=\frac{1}{N} \sum_{i=1}^{N}[R S C S-\overline{R S C S}]^{2} \\
\operatorname{STD}(z)=\left\{\frac{1}{N} \sum_{i=1}^{N}[R S C S-\overline{R S C S}]^{2}\right\}^{1 / 2}
\end{gathered}
$$
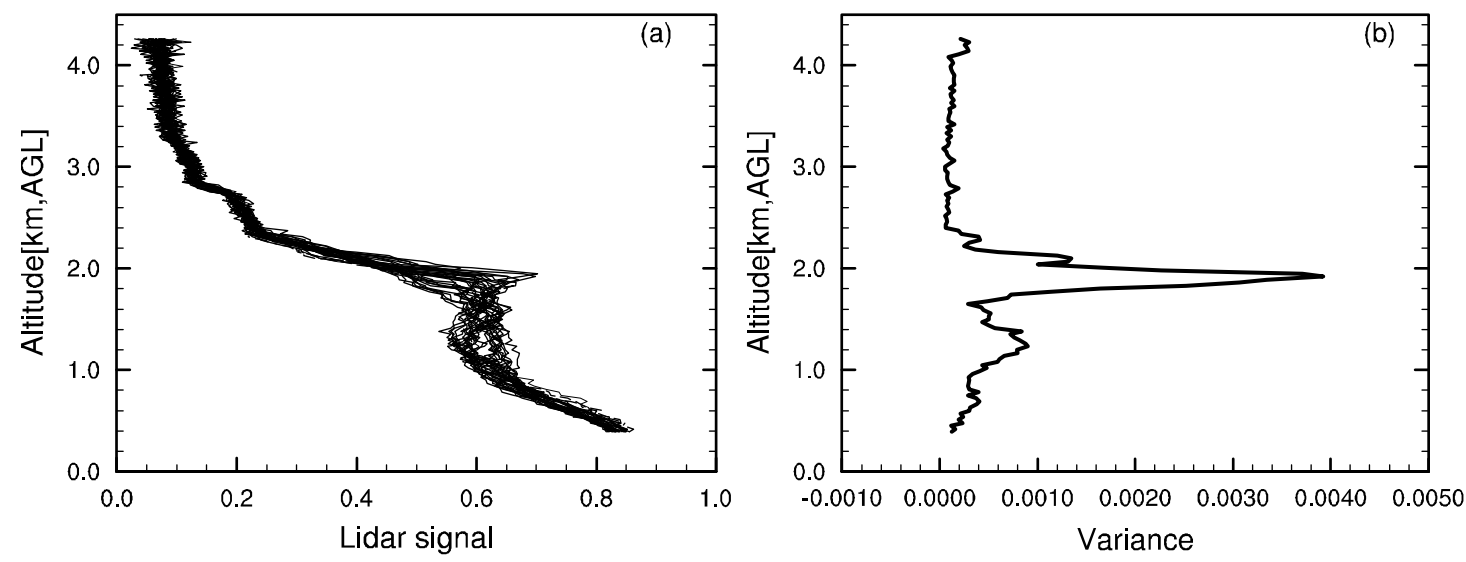

Figure 7. (a) 31 vertical RSCS profiles between 05:15-05:45 UTC (1 min interval) on 10 September 2010 over SACOL, (b) vertical profile of temporal variance (VAR).

\section{Improvement of Some Classical Methodologies}

Most of the above methodologies have been widely applied to different lidar types such as Doppler lidar [109,110], MPL [111,112], and ceilometers [113-115] to estimate the ABLH or MLH. However, it is not hard to see that most of them are not robust enough, there are more or less shortcomings. For example, most of the methods are susceptible to clouds and multiple aerosol layers, shown as Figure 8, in the morning on 28 July 2007 over SACOL, the height retrieved from FIT is the top of RL, while the GM, HAAR, and MHT capture the top of ground aerosol layer and the growing CBL. For the cloudy day 12 June 2007, the upper edges of the cloud layers were retrieved, the methods were not able to define the ABLH. To improve the ABLH determination, some classical methodologies are used in combination, e.g., the combined use of (1) GM and VAR, (2) threshold method and WCT, (3) FIT and WCT, in addition, (4) a STRAT-2D (2D version of structure of the atmosphere) algorithm [116], which includes an edge detection method [117] based on both vertical and temporal gradients in the attenuated backscatter signal. The improved versions are summarized in Table 3.
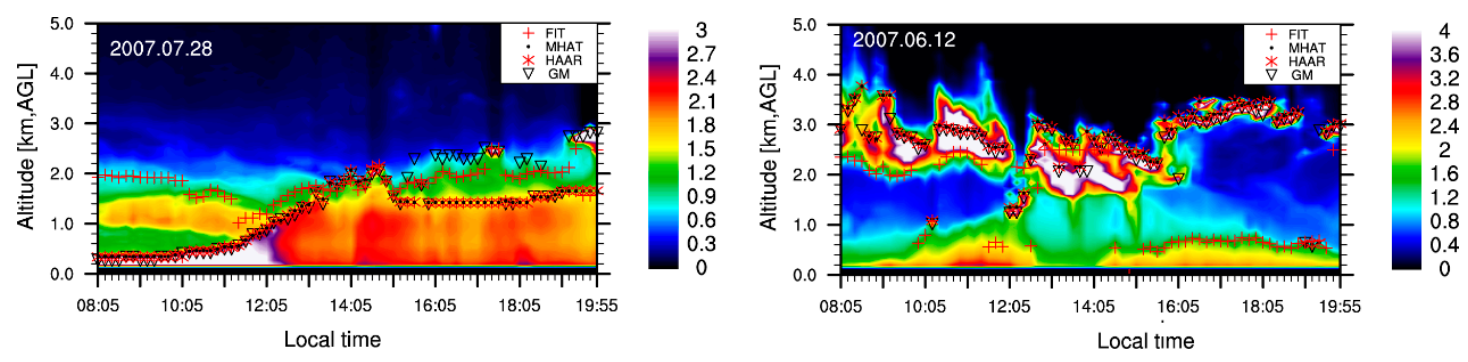

Figure 8. Time-height cross-section of the RSCS provided by the MPL over SACOL, with height directly determined from first-order gradient method (GM), HAAR/MHAT wavelet covariance transform, and ideal profile fitting (CFM) on 28 July 2007 and on 12 June 2007. 
Table 3. Improved versions of some classical methodologies in Table 2 (GM, gradient method; VAR, variance analysis; WCT, wavelet covariance transform; FIT, ideal profile fitting).

\begin{tabular}{|c|c|c|c|}
\hline Methods & Steps & Main Shortcomings & Examples of References \\
\hline $\begin{array}{l}\text { Combination of GM } \\
\text { and VAR }\end{array}$ & $\begin{array}{l}\text { variance analysis providing } \\
\text { average reference height } \\
\text { gradient analysis on signal } \\
\text { profile around the } \\
\text { reference height }\end{array}$ & $\begin{array}{l}\text { - only suitable for } \\
\text { daytime CBL }\end{array}$ & $\begin{array}{l}\text { Lammert (2004) } \\
\text { Martucci et al. (2010) }\end{array}$ \\
\hline $\begin{array}{l}\text { Combination of } \\
\text { threshold method } \\
\text { and WCT }\end{array}$ & $\begin{array}{l}\text { - } \quad \text { threshold definition } \\
\text { finding the altitude where } \\
\text { the wavelet covariance } \\
\text { exceeds the threshold }\end{array}$ & $\begin{array}{l}\text { universal lack of the } \\
\text { determined thresholds }\end{array}$ & Baars et al. (2008) \\
\hline $\begin{array}{l}\text { Combination of FIT } \\
\text { and WCT }\end{array}$ & $\begin{array}{l}\text { - wavelet covariance analysis } \\
\text { providing first guess of } \\
\text { ABLH for curve fitting } \\
\text { - ABLH determination by the } \\
\text { curve fitting }\end{array}$ & $\begin{array}{l}\text { - } \quad \text { relatively high } \\
\text { computation cost }\end{array}$ & Sawyer and Li (2013) \\
\hline $\begin{array}{l}\text { 2-D structure of the } \\
\text { atmosphere (START-2D) }\end{array}$ & $\begin{array}{l}\text { determination of the } \\
\text { altitudes of } 3 \text { major aerosol } \\
\text { gradients and the cloud base } \\
\text { heights by START-2D } \\
\text { define one of the determined } \\
\text { aerosol gradient heights as } \\
\text { the ABLH through } \\
\text { considering the temporal } \\
\text { continuity or } \\
\text { variance analysis }\end{array}$ & $\begin{array}{l}\text { - other assistant methods } \\
\text { such as threshold } \\
\text { method is required }\end{array}$ & $\begin{array}{l}\text { Morille et al. (2007) } \\
\text { Haeffelin et al. (2012) } \\
\text { Pal et al. (2013) }\end{array}$ \\
\hline $\begin{array}{l}\text { Height restriction for } \\
\text { some classical } \\
\text { methodologies }\end{array}$ & $\begin{array}{l}\text { - determination of upper } \\
\text { limit height } \\
\text { - ABLH determination below } \\
\text { the height }\end{array}$ & $\begin{array}{l}\text { the subjective or } \\
\text { statistical height } \\
\text { threshold } \\
\text { lacks universality }\end{array}$ & $\begin{array}{l}\text { Yang et al. (2013) } \\
\text { Li et al. (2017) } \\
\text { Dang et al. (2019) }\end{array}$ \\
\hline
\end{tabular}

\subsection{The Combination of GM and VAR}

To overcome the disadvantage that the GM is particularly sensitive to the local structures of the signal, as well as the low resolution of MLH (mean MLH over some time intervals) resulted from the VAR, Lammert [118] combined the VAR and GM to detect the MLH. In detail, the VAR is used to detect the presence of convective mixing and to constrain the gradient analysis to an altitude range. Lammert and Bösenberg [108] analyzed the variance on $30 \mathrm{~min}$ intervals for lidar datasets and yielded 30-min-averaged MLH. Within the 30 min intervals, the GM was applied on every individual signal profile with the resolution of the measurement system (10 s) within an altitude range around the VAR-determined 30-min-averaged MLH, resulting in more accurate series of MLH with resolution of $10 \mathrm{~s}$. The combination method is also described by Hennemuth and Lammert [42] (a flowchart is shown as Figure 9). 


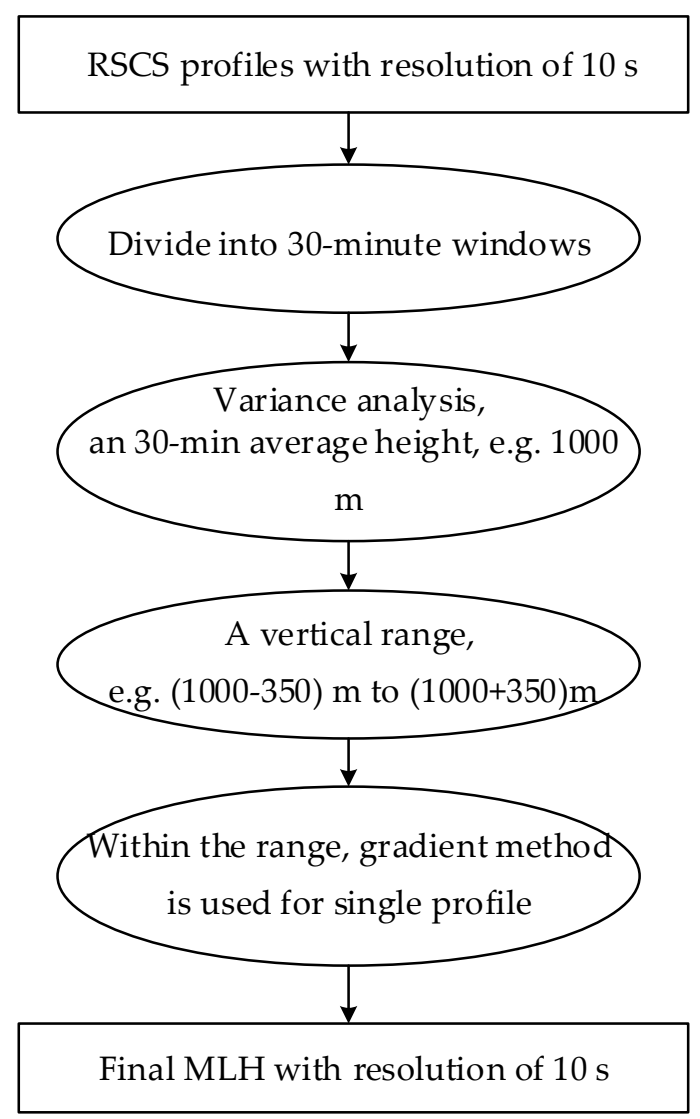

Figure 9. Flowchart for the combination of the VAR and GM in Hennemuth and Lammert [42].

In addition, combined the GM and VAR, Martucci et al. [119,120] proposed the temporal-height-tracking (THT) algorithm. The time series of CBLH can be determined by following 4 procedures:

1. For RSCS profile with time resolution of $60 \mathrm{~s}$, the single $G S_{i}$ and $\operatorname{Var}_{i}$ profiles provide single evaluations of the MLH (for $1.5 \mathrm{~h}$ measurement, $i$ goes from 1 to 90 ), the moving variance analysis is applied to each $i$-profile within the temporal interval $[i-N / 2, i+N / 2], N=10$.

2. An average signal gradient profile and a variance profile are calculated over a time interval of $30 \mathrm{~min}$, named $\overline{G S}$ and $\overline{V a r}$. The reference height $\left(h_{r e f}\right)$ is defined as the middle position of the heights of the $\overline{G S}$ minimum and the $\overline{V a r}$ maximum, the related error is $\sigma_{r e f}=\sqrt{\sigma_{\overline{G S}}^{2}+\sigma_{\overline{V a r}}^{2}}$, where the standard deviations of $\overline{G S}$ and $\overline{V a r}$ are calculated over the $30 \mathrm{~min}$ average at $h_{\text {ref }}$.

3. For $i=1$, within a vertical range $h_{j} \in\left[0.85\left(h_{r e f}-\sigma_{r e f}\right)-1.15\left(h_{r e f}+\sigma_{r e f}\right)\right], C B L H_{1}$ is determined as the middle position of the local minimum of $G S_{1}$ and local maximum of the $\operatorname{Var}_{1}$.

4. For $i=2,30$, within the vertical range $h_{j} \in\left[0.85\left(C B L H_{i-1}-\sigma_{C B L H_{i-1}}\right)-1.15\left(C B L H_{i-1}-\sigma_{C B L H_{i-1}}\right)\right]$, the $C B L H_{i}$ is determined as the middle position of the local minimum of $G S_{i}$ and local maximum of the $\operatorname{Var}_{i}$. For next time window $(i=31,60)$, procedures 2 to -4 are repeated, a simple scheme for THT algorithm is shown as Figure 10. 


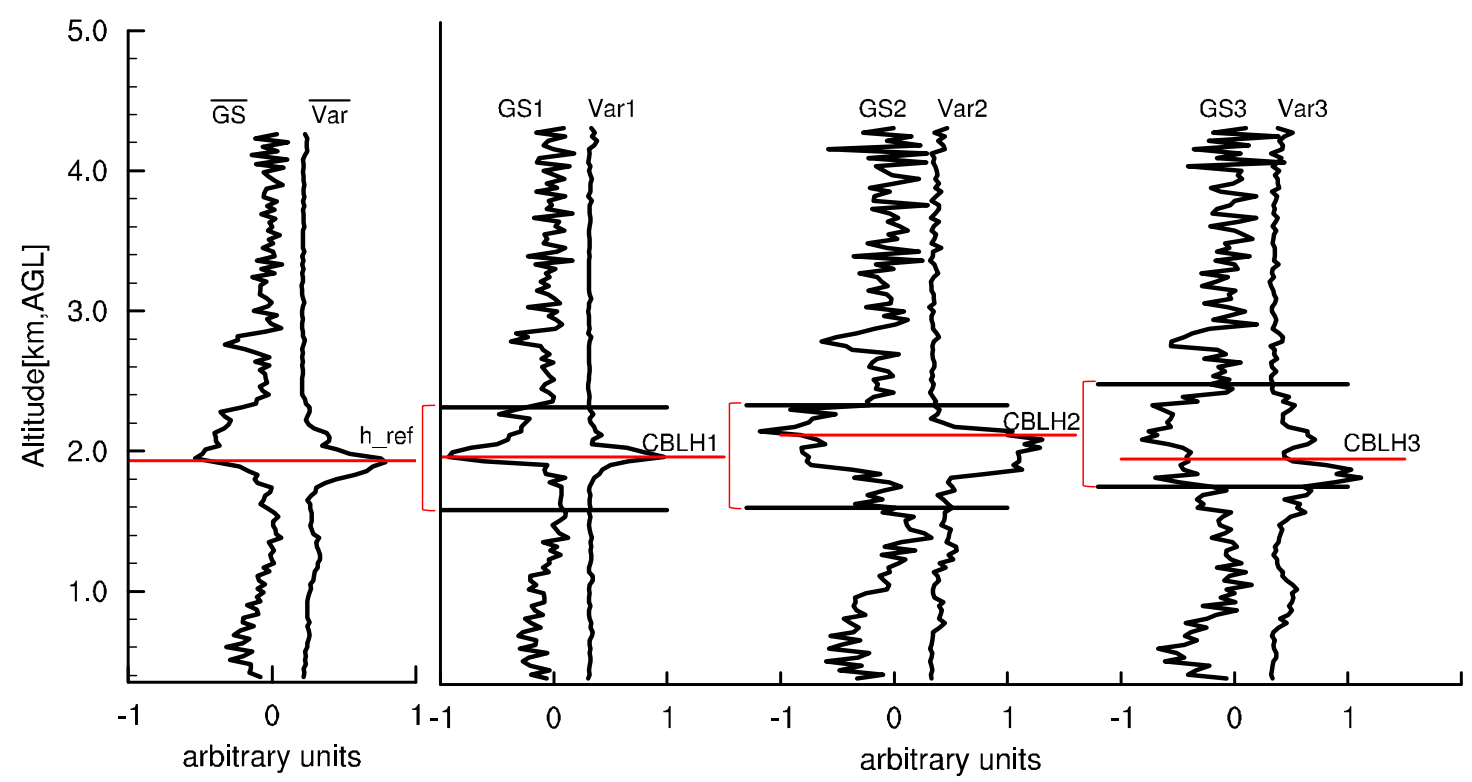

Figure 10. Synopsis of the temporal-height tracking (THT) algorithm in Martucci et al. [119]. The profiles of the $\overline{G S}$ and $\overline{V a r}$ are averaged over the interval $30 \mathrm{~min}$, for $i=1,30$, profile of the $G S_{i}$ is the single signal gradient profile at $i$ step, $\operatorname{Var}_{i}$ is calculated by the moving variance within the temporal interval $[i-N / 2, i+N / 2], N=10$.

The combination of the GM and the VAR theoretically should perform better than the GM when there are several local minima in RSCS gradient profile-either atmosphere- or noise-induced. Meanwhile, it can yield instantaneous MLH with the resolution of observation system compared to the VAR being used alone. Similar to VAR, the combined method is also only applicable to daytime CBL.

\subsection{The Combination of Thereshold Method and WCT}

Baars et al. [121] defined some thresholds to improve the WCT which is developed by Brooks [93]. A local maximum of covariance transform $w_{f}(a, b)$ generally occurs at the ABL top, Baars defined a threshold of 0.05 for $w_{f}(a, b)$ to identify a significant gradient and to omit the weak gradients. The height where a local maximum of $w_{f}(a, b)$ first exceeds the threshold is defined as the ABLH. In addition, the cloud base is defined as the altitude where $w_{f}(a, b)$ is smaller than the preset threshold of -0.1 because the $w_{f}(a, b)$ generally becomes negative and presents a local minimum at the cloud base. Thus, only the signal below the cloud base is used to retrieve the ABLH to eliminate the interference of cloud. The use of the thresholds can effectively omit the influence of weak gradients and the interference of cloud outside the $\mathrm{ABL}$, however, the definition and application of the thresholds lack universality.

\subsection{The Combination of FIT and WCT}

The WCT is able to automatically define the time series of ABLH from simple RSCS profiles as it requires little prior information about the atmosphere or observation instrument, however, the technique is easily interfered by the signal backscattered by high clouds and multiple aerosol layers. The FIT is less affected by the multiple layers because of the use of idealized backscatter profile, however, the initial guess of the ABLH is essential for fitting process while it is difficult to automatically provide appropriate initial values. Sawyer and Li [104] combined the advantages of the two algorithms, the WCT automatically determines the ABLH to provide the first guesses for the FIT. Thus, the combined method is able to detect the ABLH automatically and is less sensitive to multiple cloud or aerosol layers, although it requires relatively high computation cost. 


\section{4. $2 D$ Version of Structure of the Atmosphere (STRAT-2D)}

Morille et al. [99] proposed a technique called STRAT (structure of the atmosphere) to detect the MLH by applying a first derivative of the Gaussian filter (GF1D) on RSCS profile. The GF1D is applied to obtain the smoothed gradient profile. Haeffelin et al. [116] improved the algorithm and developed an algorithm called STRAT-2D which includes an edge detection method [117] based on both vertical and temporal gradients in the backscatter signal. Using Sobel 2-D derivation operators [122], the algorithm retrieves MLH by deriving gradients in two directions $G=\sqrt{G_{x}^{2}+G_{y}^{2}}$, vertical $G_{y}$ and horizontal $G_{x}$. Relative to the original STRAT, the main improvement of the 2D version of the algorithm is that it is able to guarantee the temporal consistency of the resulted MLH. At each time step, the STRAT-2D algorithm yields 3 different gradient heights: Two of the strongest gradient heights $\left(\mathrm{MLH}_{\text {large, }}, \mathrm{MLH}_{\text {second }}\right)$ and the lowest gradient height $\left(\mathrm{MLH}_{\mathrm{low}}\right)$. The $\mathrm{MLH}$ is defined as one of the determined three minimum gradient heights at which the signal gradient is larger than a fixed threshold or it has neighbor value larger than the threshold (for details see Haeffelin et al. [116]).

Pal et al. [7] combined the STRAT-2D and VAR and determined the MLH through a two-step procedure. Firstly, the STRAT-2D algorithm is applied to determine the locations of three major aerosol gradients and the cloud base heights with a temporal resolution of $10 \mathrm{~min}$. Secondly, it defines the average MLH over $1 \mathrm{~h}$ time interval through variance analysis. The MLH with a resolution of $10 \mathrm{~min}$ is returned as one of the determined heights that is closest to the average height over $1 \mathrm{~h}$ (a flowchart is shown as Figure 11). Schween [113] used the STRAT-2D algorithm to ceilometer data to determine the MLH. The STRAT-2D algorithm takes both temporal and spatial gradients of backscatter signal into account and provides three to five (including cloud base) height candidates for MLH. The technique is a good choice for retrieving MLH in multiple-layer conditions although other additional assistant methods such as the threshold method or variance analysis is necessary.

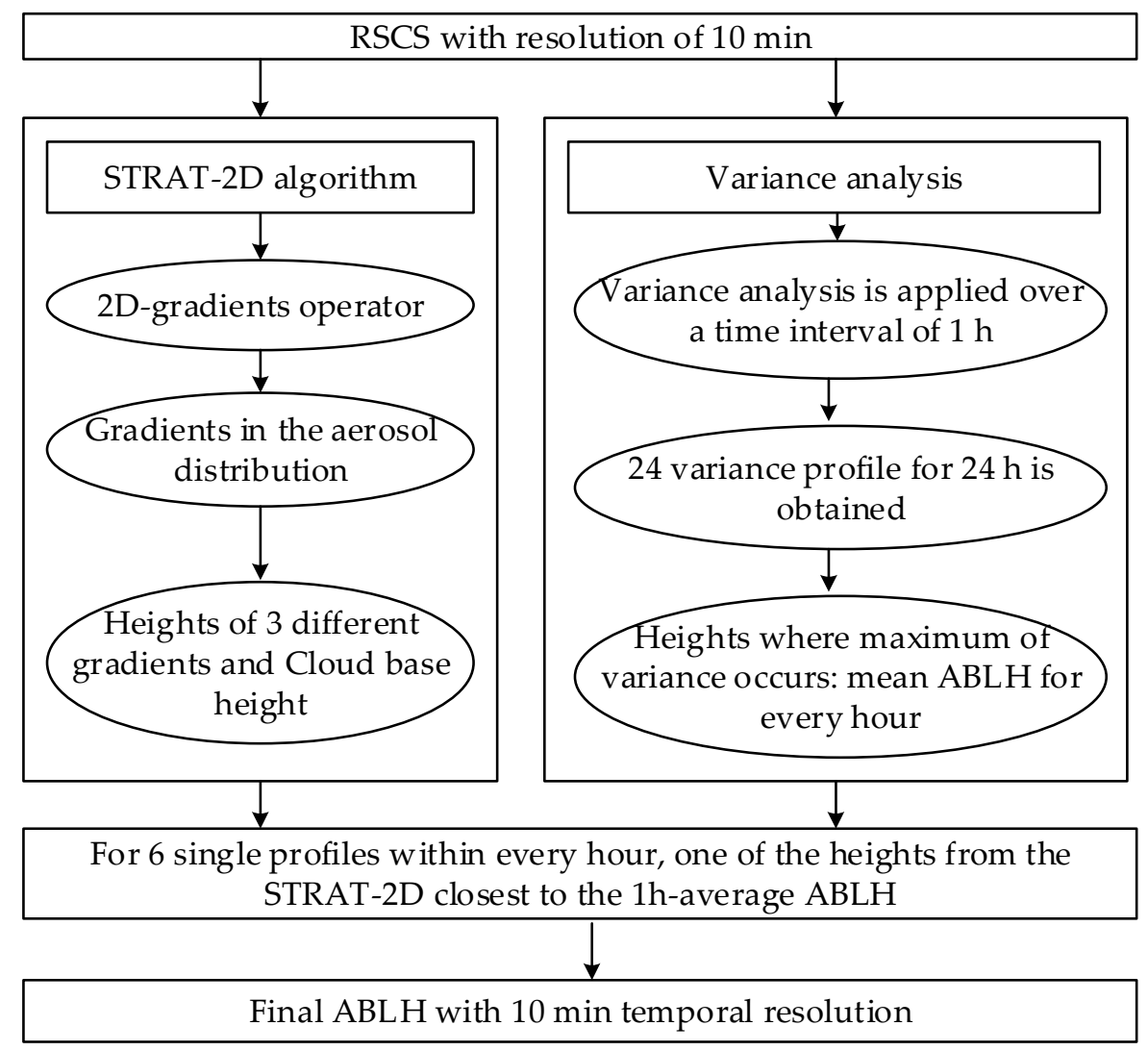

Figure 11. Flowchart for the combination of the STRAT-2D (structure of the atmosphere, 2D version) and VAR in Pal et al. [7]. 


\subsection{Height Restriction for Some Classical Methodologies}

In addition to above improved versions, some studies set height restriction to some classical methodologies to omit the signal backscattered by some unexpected stratifications, that is, the lidar signal only below the preset height is used to define the MLH or ABLH. For example, Wang et al. [123] determined the ABLH from lidar data by using the GM below an altitude of $2.5 \mathrm{~km}$. However, the subjective threshold may not apply to other regions with different ABL structures. Yang et al. [124] defined the first significant RSCS gradient peak near the cloud layer as the upper limit, then below which the position of the deepest valley of the gradient profile is defined as the MLH [125]. Thus, the information of the upper aerosol layers will be omitted, however, the operation is not suited when the cloud base is lower than the top of ML. Li et al. [126] used the convective condensation height (CCL) to estimate the base of clouds that are decoupled from the ABL, only the RSCS below the CCL are used to eliminate the interference of clouds. This method is a good choice in cloudy situations if thermodynamic profiles are available when CCL can be accurately calculated.

Dang et al. [56] defined an objective upper limiter altitude to reduce the interference of RL and cloud layer on daytime MLH retrieval. The top limiter altitude is determined according to the cloud location, whether the cloud is outside or within the ABL is classified through judging if the strongest signal gradient below the cloud base is lower than a preset threshold. The top limiter and the ABLH determined below the height restriction on 28 July and 12 June 2007 over SACOL are shown as Figure 12. With the top limiter, the diurnal variations of ABLH on two day are successfully retrieved although the local structures of the signal affect the temporal continuity of the resulted ABLH especially from GM. The main challenge for eliminating the cloud disturbance on ABLH or MLH determination is the accurate estimation of cloud location, meanwhile, it is difficult to accurately define the ABLH in the situations where the cloud layers are within the ABL but not at the ABL top.
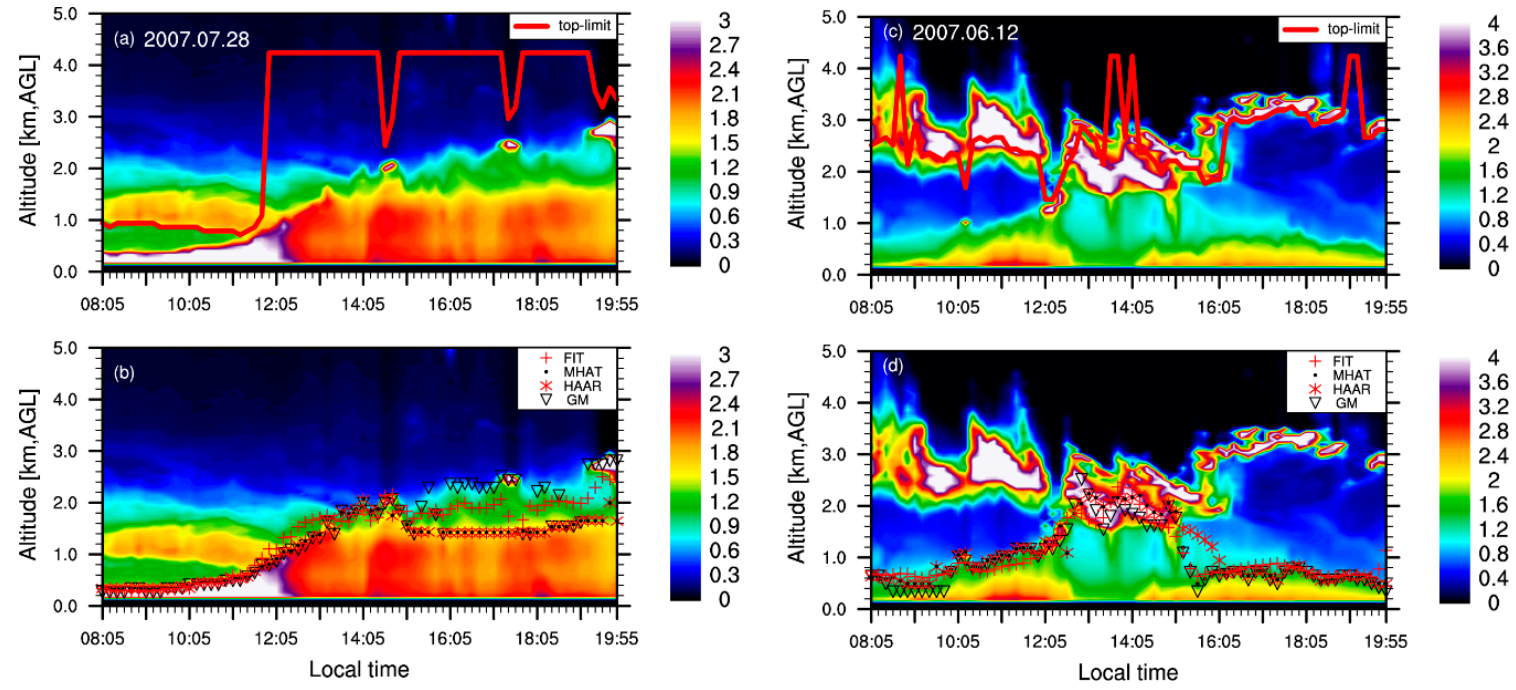

Figure 12. Same as in Figure 8, the top limiter in $(\mathbf{a}, \mathbf{c})$ represents the upper altitude defined in Dang et al. [56], the ABLH in (b,d) determined from the HM, HAAR, MHAT, and CFM below the top limiter.

\section{New Techniques Developed Recently}

\subsection{New Techniques Based on Single-Wavelength Lidar}

In recent years, some sophisticated algorithms have been proposed and developed to determine the MLH or ABLH from lidar measurements by incorporating advanced techniques such as image edge detection, points grouping, and layer tracking, etc. Some of them have not been widely tested and used. For example, Xiang et al. [52] proposed a technique based on the image edge detection 
(IEDM). The ABLH is detected by taking a series of digital image processing operations, including Gaussian filter and morphology detection. Bruine et al. [54] proposed a method called pathfinder, applying graph theory to track the diurnal development of the ABLH. In addition, cluster analysis is a statistical method (CAM) which has been widely used in meteorology and climatology studying. Toledo et al. [127] first applied the technique to lidar measurement for ABLH estimation. CAM is used to determine the ABLH as a function of both the RSCS profiles and the statistical analysis of the RSCS profiles in terms of its variance. Thus, the technique makes available a single result when the gradient-based techniques and the variance analysis provide different ones.

A solution utilizing an extended Kalman Filter (EKF) to trace the evolution of the ABLH from a ground-based lidar has been recently tested and developed $[128,129]$. The technique is preliminarily outlined by Tomás et al. [130] upon the previous works by Rocadenbosch et al. [131,132]. An oversimplified idealized profile (Equation (16)) is modeled by an erf-like function. The filter adaptively fits the idealized profile to the lidar measured signal profile and defines the ABLH by minimizing the mean-squared error between the estimated profile and the backscatter signal profile over time in a statistical sense.

$$
h\left(R ; R_{b l}, a, A, c\right)=\frac{A}{2}\left\{1-\operatorname{erf}\left[\frac{a}{\sqrt{2}}\left(R-R_{b l}\right)\right]\right\}+c
$$

where $R_{b l}$ is the range position marking the instantaneous $\mathrm{ABLH}$ (the point where the gradient of $h$ has its minimum value), $a$ is a scaling factor to EZT, $A$ is the amplitude of the erf transition, and $c$ is the FT average molecular-backscatter value. The EKF technique is based on estimating four time-adaptive coefficients of the defined erf-like curve model $h\left(R ; R_{b l}, a, A, c\right)$, four time-variant parameters form the state vector $x_{k}\left(x_{k}=\left[R_{b l, k}, a_{k}, A_{k}, c_{k}\right]^{t}\right)$ at each time $t_{k}$.

The filter requires two models to operate $[39,133,134]$ :

(i) The state-vector model, which models the dynamics of the state-vector from time $t_{k}$ to $t_{k+1}$ by a Gauss-Markov transition model:

$$
x_{k+1}=x_{k}+w_{k}
$$

where $w_{k}$ is the state-noise vector with diagonal covariance matrix $Q_{k}=\operatorname{diag}\left[\sigma_{b l^{\prime}}^{2}, \sigma_{a}^{2}, \sigma_{A^{\prime}}^{2}, \sigma_{c}^{2}\right]$, $\sigma_{b l}^{2}, \sigma_{a}^{2}, \sigma_{A}^{2}, \sigma_{c}^{2}$ represent the standard deviations associated to the state-vector components $R_{b l}, a, A, c$.

(ii) The measurement model, the observation vector $z_{k}$ (the lidar measurements at each time $t_{k}$ ) is related to $x_{k}$ :

$$
z_{k}=h\left(x_{k}\right)+v_{k}
$$

where $h\left(x_{k}\right)$ is the erf function (Equation (16)), $v_{k}$ is the observation noise at time $t_{k}$ with the covariance matrix $V_{k}$, which is estimated by calculating the range-dependent observation noise variance from the lidar SNR [135].

The EKF technique benefits from the knowledge of past ABLH estimates as well as their associated errors and estimates the time-dependent ABLH [129]. Meanwhile, the technique is able to work under low SNR atmospheric scenes without need for long time averaging and range smoothing [128].

\subsection{ABLH Determination from Multi-Walelength Lidar}

For a long time in the past, the lidar measurement of MLH or ABLH was mainly based on the single-wavelength lidar system, which is challenging in complex situations such as in appearance of cloud or multiple aerosol layers. In recent years, the multi-wavelength lidar has begun to be used in ABL research when the aerosol color ratio and depolarization ration can be obtained from multi-wavelength information. Several studies have proved that the properties of the atmospheric particles differ at different heights, meanwhile, different aerosol types have different color ratio and depolarization ratio $[136,137]$. Based on the observation from the two-wavelength polarization lidar system located at Wuhan University in China, Liu et al. [138] found that locally, most of the particles in the upper atmosphere (above $1500 \mathrm{~m}$ ) are molecules with low color ratio, while the particles in the 
near ground (below) are mainly aerosol particles with high color ratio; besides, the similar particles gather together.

Liu et al. [138] proposed a two-wavelength algorithm called particle distribution method (PDM) to determine the ABLH based on the particle distribution, which is established by using the aerosol color ratio (CR) and depolarization ratio (DR). A k-means method [53] was utilized to divide the atmospheric particles into two categories, the molecular and aerosol clusters (cluster 1 represents the molecules above the top of $\mathrm{ABL}$, while the cluster 2 represents the aerosols within the $\mathrm{ABL}$ ). The height where a change from a cluster to the other one is defined as the ABLH. The technique effectively eliminates the interference of the multi-layer aerosols on ABLH determination, however, the technique performs poor when RL exists. To overcome the issue, Liu et al. [139] improved the PDM in two aspects and proposed the particle cluster method (PCM). First, the backscattering signal (BC) was used rather than the DR in the PDM. Second, Gaussian mixture model [76] was used to replace the k-means method in PDM to classify the particles. By test, the PCM utilizing the particle clustering method performed better on ABLH determination than PDM in complex aerosol situations.

Based on a multi-wavelength lidar system (emits at 355, 532 and $1064 \mathrm{~nm}$ ), Bravo-Aranda et al. [140] introduced a new method called POLARIS, in which the WCT is both applied to the RSCS profile and the perpendicular-parallel signal ratio profile (low ratio values might be related to spherical particle shape and vice versa). The technique is able to define aerosol layer coupled to the ABL if the aerosol particle shape is different enough to be detected by the depolarization profile, which is a great improvement for ABLH determination.

\section{Summary and Conclusions}

Aerosol lidar is a powerful active remote sensing tool that has been used to estimate the ABLH for about 40 years. Its application has been favored by outstanding advantages including high temporal and vertical resolutions and automatic operation, especially the eye-safe laser and negligible multiple-scattering effect for MPL. The blind zone related to the overlap error has to be considered when the lidar data are used, the data in lowest tens of meters to a few hundred meters (depends on the lidar system) is not available. The range limitations can be compensated through the simultaneous operation of other remote sensing instruments such as a sodar or a mini-sodar which perform great on shallow ABLH estimation (about $50 \mathrm{~m}$ and 50-1000 $\mathrm{m}$ above the ground).

The aerosol lidar is able to determine the height of surface aerosol layer when it is higher than the lidar blind zone. Theoretically, for well-mixed CBL, the lidar-determined height can be considered as the "true" measure of the mixing-layer height, which is identical to the radiosonde-determined CBLH; for stable NBL, the lidar-determined height is either the height of RL or the ground mechanical driven mixing-layer height, the latter should be identical to the height of ground inversion layer. For the transition periods in early morning (EMT) and late afternoon (EET), the lidar determined height may be the height to which the aerosol particles have mixed in the past rather than the height to which they are presently being mixed. In actual application, the lidar-defined ABLH is generally slightly higher than that derived from temperature profiles. This can be explained by the fact that the most energetic convective plumes penetrate into the stable or the inversion layer, thereby transport the aerosol to levels above the average height of inversion or stable layer bottom. Most previous research has focused on the daytime MLH (or CBLH) estimation, the ABLH estimation is more complex for nocturnal SBL and the transition periods, there is a general need for more work on the SBL and the ABL during the EMT and EET periods.

Several techniques have been proposed and developed to obtain the ABLH from aerosol lidar. The classical methodologies include visual inspection, threshold method, gradient methods (first derivative (GM), second derivative (IPM), the logarithm gradient (LGM) and the cubic root gradient (CRGM)), ideal profile fitting (FIT), wavelet covariance transform (WCT), and variance analysis (VAR). Most of them perform great when the signal structure is simple in clear-sky conditions and show the characteristics of ABL clearly. The main challenge is under complex signal structure conditions caused 
by multiple-layer aerosol layers (advected or elevated), cloud layers as well as noise. Because of the interferences caused by them, many of the lidar-based techniques are unable to process the large data set automatically. To overcome the shortcomings, on the one hand, some of the classical methodologies were improved. One of the popular ways is to use at least two methods in combination manner to make up for each other's shortcomings for example, the combined use of GM and VAR, the WCT and FIT, the threshold method and WCT. A technique called START-2D (structure of the atmosphere, 2D version) performs well under multiple layer situations by using a temporal-vertical gradient. On the other hand, some studies imposed height constraints to the algorithms, defining an upper altitude to omit the noise signal generated by multiple layers outside the ABL. However, the ABLH determination in cloudy situations is still changeling and there are so far some unresolved issues. For example, when the cloud is within the ABL but not at the ABL top, the lidar estimation of ABLH is quite difficult. To reduce the cloud interference on ABLH determination, the identification of cloud layer should be further studied and the location of the cloud layer should be determined more accurately. Meanwhile, the influence of cloud layers on the diurnal development of ABL is necessary to be further studied.

By incorporating some advanced techniques such as image edge detection, points grouping, and layer tracking, some techniques were proposed and developed recently such as image edge detection method (IEDM), cluster analysis method (CAM), and an extended Kalman Filter (EKF) algorithms. The techniques put forward some new aspects for the estimation of ABLH from lidar. Furthermore, multi-wavelength lidar systems are coming into view, the profiles of the aerosol color ratio (CR), depolarization ratio (DR), and perpendicular-parallel signal ratio are used to assist the ABLH estimation. The example techniques include the particle distribution method (PDM), particle cluster method (PCM), and the POLARIS (PBL height estimation based on lidar depolarization) method. Most of the new techniques have been tested and showed perform well, however, the application of them is currently limited. Are they able to define the ABLH in any complex situations with high accuracy? Can the shallow ABLH be defined? The recently developed techniques should be further applied and tested to prove if they have good prospects.

Lidar estimation is one of the profile measurements of ABLH or MLH, the other possibility for ABLH estimation is the application of the simple PBL parameterizations or numerical models. The profile measurement is generally the first option if data is available. However, continuous profile measurements for the operational determination of ABLH are not generally available, meanwhile, the spatial and temporal representativeness of ABLH derived from profile measurements need further studies. Numerical weather predication (NWP) models have been used in the practice of the meteorological and environmental service. In the NWP models, PBL schemes are used to parameterize the unresolved turbulent vertical fluxes of heat, momentum, and constituents such as moisture within the PBL and throughout the atmosphere. For different schemes, different assumptions are used, which may be the root cause of the models' performance difference. One of the promising applications of the lidar-determined instantaneous ABLH is to estimate the simulated results from the NWP models and to continuously improve the PBL parameterizations in the models. Meanwhile, what the most important for NWP models are the initial and boundary conditions, assimilating the lidar derived ABLH into the models is expected to provide more accurate meteorological initials and boundaries for NWP models, which will be a very attractive approach to let the lidar data serve numerical models when there are numerous lidar observations at present. Thus, it is possible to substitute NWP model output for profiles measurements of ABLH in the future. The output from NWP models are expected to provide more accurate meteorological fields for dispersion models or environmental models, and the air quality simulation is expected to improve.

Author Contributions: Y.Y. and X.-M.H. conceived the study, R.D. reviewed and summarized the literatures. R.D. wrote, Y.Y., X.-M.H., Z.W. and S.Z. edited the paper.

Funding: This research was funded by National Natural science Foundation of China (41375109), the National Key R\&D Program of China (2017YFC1502102). 
Acknowledgments: The authors would like to thank all researchers who made great contributions to studying of the atmospheric boundary layer, especially the researches whose achievement has been cited in this study. Their studies provide reference and reliable basis for this review. The authors would also like to thank the Semi-Arid Climate and Environment Observatory of Lanzhou University (SACOL) for data observation support, as well as Gansu meteorological Bureau for providing Radiosonde observations.

Conflicts of Interest: The authors declare no conflict of interest.

\section{References}

1. Stull, R.B. An introduction to boundary layer meteorology. In Atmospheric Sciences Library; Springer: Berlin, Germany, 1988; Volume 8, p. 89.

2. Seibert, P.; Beyrich, F.; Gryning, S.-E.; Joffre, S.; Rasmussen, A.; Tercier, P. Review and intercomparison of operational methods for the determination of the mixing height. Atmos. Environ. 2000, 34, 1001-1027. [CrossRef]

3. Garratt, J.R. The Atmospheric Boundary Layer; Cambridge University Press: Cambridge, UK, 1992.

4. Beyrich, F.; Gryning, S.E.; Joffre, S.; Rasmussen, A.; Seibert, P.; Tercier, P. Mixing Height Determination for Dispersion Modelling-A Test of Meteorological Pre-Processors. In Air Pollution Modeling and Its Application XII.; Springer: Boston, USA, 1998.

5. Haman, C.L.; Lefer, B.; Morris, G.A. Seasonal variability in the diurnal evolution of the boundary layer in a near-coastal urban environment. J. Atmos. Ocean. Technol. 2012, 29, 697-710. [CrossRef]

6. Granados-Muñoz, M.J.; Navas-Guzmán, F.; Bravo-Aranda, J.A.; Guerrero-Rascado, J.L.; Lyamani, H.; Fernández-Gálvez, J.; Alados-Arboledas, L. Automatic determination of the planetary boundary layer height using lidar: One-year analysis over southeastern Spain. J. Geophys. Res. Atmos. 2012, 117. [CrossRef]

7. Pal, S.; Haeffelin, M.; Batchvarova, E. Exploring a geophysical process-based attribution technique for the determination of the atmospheric boundary layer depth using aerosol lidar and near-surface meteorological measurements. J. Geophys. Res.-Atmos. 2013, 118, 9277-9295. [CrossRef]

8. Seibert, P.; Beyrich, F.; Gryning, S.E.; Joffre, S.; Rasmussen, A.; Tercier, P. Mixing height determination for dispersion modeling, Report of Working Group 2. In Harmonization in the Preprocessing of Meteorological Data for Atmospheric Dispersion Models. COST Action 710. Final Report; Office for official Publications of the European Communities: Luxembourg, 1998.

9. Cooper, D.I.; Eichinger, W.E. Structure of the atmosphere in an urban planetary boundary layer from lidar and radiosonde observations. J. Geophys. Res. Atmos. 1994, 99, 22937-22948. [CrossRef]

10. Seidel, D.J.; Ao, C.O.; Li, K. Estimating climatological planetary boundary layer heights from radiosonde observations: Comparison of methods and uncertainty analysis. J. Geophys. Res. Atmos. 2010, 115. [CrossRef]

11. Jeričević, A.; Kraljević, L.; Grisogono, B.; Fagerli, H.; Večenaj, Ž. Parameterization of vertical diffusion and the atmospheric boundary layer height determination in the EMEP model. Atmos. Chem. Phys. 2010, 10, 341-364. [CrossRef]

12. Norton, C.L.; Hoidale, G.B. The diurnal variation of mixing height by month over White Sands Missile Range, New Mexico. Mon. Weather Rev. 1976, 104, 1317-1320. [CrossRef]

13. Wang, X.; Wang, K. Homogenized Variability of Radiosonde Derived Atmospheric Boundary Layer Height over the Global Land Surface from 1973 to 2014. J. Clim. 2016, 29, 6893-6908. [CrossRef]

14. Basha, G.; Kishore, P.; Ratnam, M.V.; Babu, S.R.; Velicogna, I.; Jiang, J.H.; Ao, C.O. Global climatology of planetary boundary layer top obtained from multi-satellite GPS RO observations. Clim. Dyn. 2019, 52, 2385-2398. [CrossRef]

15. Seidel, D.J.; Zhang, Y.; Beljaars, A.C.M.; Golaz, J.C.; Jabobson, A.R.; Medeiros, B. Climatology of the planetary boundary layer over the continental United States and Europe. J. Geophys. Res. Atmos. 2012, 117. [CrossRef]

16. Guo, J.; Miao, Y.; Zhang, Y.; Liu, H.; Li, Z.; Zhang, W.; He, J.; Lou, M.; Yan, Y.; Bian, L. The climatology of planetary boundary layer height in China derived from radiosonde and reanalysis data. Atmos. Chem. Phys. 2016, 16, 13309-13319. [CrossRef]

17. Moores, W.H.; Caughey, S.J.; Readings, C.J.; Milford, J.R.; Mansfield, D.A.; Abdulla, S.; Guymer, T.H.; Johnston, W.B. Measurements of boundary layer structure and development over SE England using aircraft and tethered balloon instrumentation. Q. J. R. Meteorol. Soc. 1979, 105, 397-421. [CrossRef]

18. Jordi, V.G.d.A.; Duynkerke, P.G.; Weele, M.V. Tethered-balloon measurements of actinic flux in a cloud-capped marine boundary layer. J. Geophys. Res. Atmos. 1994, 99, 3699-3706. 
19. Holden, J.J.; Derbyshire, S.H.; Belcher, S.E. Tethered Balloon Observations of the Nocturnal Stable Boundary Layer in a Valley. Bound.-Layer Meteorol. 2000, 97, 1-24. [CrossRef]

20. Vernekar, K.G.; Sadani, L.K.; Brij, M.; Saxena, S.; Debaje, S.B.; Pillai, J.S.; Murthy, B.S.; Patil, M.N. Structure and growth of atmospheric boundary layer as observed by a tethered balloon payload. Indian J. Radio Space Phys. 1991, 20, 312-315.

21. Dai, C.Y.; Gao, Z.Q.; Wang, Q.; Cheng, G. Analysis of Atmospheric Boundary Layer Height Characteristics over the Arctic Ocean Using the Aircraft and GPS Soundings. Atmos. Ocean. Sci. Lett. 2011, 4, 124-130.

22. Dai, C.; Wang, Q.; Kalogiros, J.A.; Lenschow, D.H.; Gao, Z.; Zhou, M. Determining Boundary-Layer Height from Aircraft Measurements. Bound.-Layer Meteorol. 2014, 152, 277-302. [CrossRef]

23. Galmarini, S.; Attié, J.L. Turbulent Transport atthe Thermal Internal Boundary-Layer top: Wavelet Analysis of Aircraft Measurements. Bound.-Layer Meteorol. 2000, 94, 175-196. [CrossRef]

24. Beyrich, F. On the use of SODAR data to estimate mixing height. Appl. Phys. B Photophys. Laser Chem. 1993, 57, 27-35. [CrossRef]

25. Beyrich, F.; Weill, A. Some aspects of determining the stable boundary layer depth from sodar data. Bound.-Layer Meteorol. 1993, 63, 97-116. [CrossRef]

26. Emeis, S.; Münkel, C.; Vogt, S.; Müller, W.J.; Schäfer, K. Atmospheric boundary-layer structure from simultaneous SODAR, RASS, and ceilometer measurements. Atmos. Environ. 2004, 38, 273-286. [CrossRef]

27. Helmis, C.G.; Sgouros, G.; Tombrou, M.; Schäfer, K.; Münkel, C.; Bossioli, E.; Dandou, A. A Comparative Study and Evaluation of Mixing-Height Estimation Based on Sodar-RASS, Ceilometer Data and Numerical Model Simulations. Bound.-Layer Meteorol. 2012, 145, 507-526. [CrossRef]

28. Lokoshchenko Mikhail, A. Long-Term Sodar Observations in Moscow and a New Approach to Potential Mixing Determination by Radiosonde Data. J. Atmos. Ocean. Technol. 2002, 19, 1151-1162. [CrossRef]

29. Beyrich, F. Mixing height estimation from sodar data-A critical discussion. Atmos. Environ. 1997, 31, 3941-3953. [CrossRef]

30. Mead, J.B.; Hopcraft, G.; Frasier, S.J.; Pollard, B.D.; Cherry, C.D.; Schaubert, D.H.; Mcintosh, R.E. A Volume-Imaging Radar Wind Profiler for Atmospheric Boundary Layer Turbulence Studies. J. Atmos. Ocean. Technol. 1998, 15, 849-859. [CrossRef]

31. Hu, M.; Zhang, P. Measuring Performance Analysis of Wind Profiling Radar. Meteorol. Sci. Technol. 2011, 39, 315-319.

32. White, A.B.; Fairall, C.W. Convective boundary layer structure observed during ROSE1 using the NOAA 915 MHz radar wind profiler. NASA STI/Recon Tech. Rep. N 1991, 92.

33. Bianco, L.; Wilczak, J.M. Convective Boundary Layer Depth: Improved Measurement by Doppler Radar Wind Profiler Using Fuzzy Logic Methods. J. Atmos. Ocean. Technol. 2002, 19, 1745-1758. [CrossRef]

34. Wilczak, J.M.; Strauch, R.G.; Ralph, F.M.; Weber, B.L.; Merritt, D.A.; Jordan, J.R.; Wolfe, D.E.; Lewis, L.K.; Wuertz, D.B.; Gaynor, J.E. Contamination of Wind Profiler Data by Migrating Birds: Characteristics of Corrupted Data and Potential Solutions. J. Atmos. Ocean. Technol. 1988. [CrossRef]

35. Angevine, W.M. Atmospheric boundary layer height measurements with wind profilers: Successes and cautions. In Proceedings of the IEEE International Geoscience \& Remote Sensing Symposium, Honolulu, HI, USA, 24-28 July 2000.

36. Liu, S.; He, W.; Liu, H.; Chen, H. Retrieval of Atmospheric Boundary Layer Height from Ground-based Microwave Radiometer Measurements. J. Appl. Meteorol. Sci. 2015, 26, 626-635.

37. Cimini, D.; Angelis, F.D.; Dupont, J.C.; Pal, S.; Haeffelin, M. Mixing layer height retrievals by multichannel microwave radiometer observations. Atmos. Meas. Tech. Discuss 2013, 6, 4971-4998. [CrossRef]

38. Crewell, S.; Lohnert, U. Accuracy of Boundary Layer Temperature Profiles Retrieved With Multifrequency Multiangle Microwave Radiometry. IEEE Trans. Geosci. Remote Sens. 2007, 45, 2195-2201. [CrossRef]

39. Saeed, U.; Rocadenbosch, F.; Crewell, S. Synergetic use of LiDAR and microwave radiometer observations for boundary-layer height detection. In Proceedings of the IEEE International Geoscience and Remote Sensing Symposium (IGARSS), 2015 IEEE international, Milan, Italy, 26-31 July 2015; pp. 3945-3948.

40. Floors, R.; Vincent, C.L.; Gryning, S.E.; Peña, A.; Batchvarova, E. The Wind Profile in the Coastal Boundary Layer: Wind Lidar Measurements;and Numerical Modelling. Bound.-Layer Meteorol. 2013, 147, 469-491. [CrossRef]

41. Spinhirne, J.D. Micro Pulse Lidar. IEEE Trans. Geosci. Remote Sens. 1993, 31, 48-55. [CrossRef] 
42. Hennemuth, B.; Lammert, A. Determination of the Atmospheric Boundary Layer Height from Radiosonde and Lidar Backscatter. Bound.-Layer Meteorol. 2006, 120, 181-200. [CrossRef]

43. Toledo, D.; Córdoba-Jabonero, C.; Adame, J.A.; Benito, D.L.M.; Gil-Ojeda, M. Estimation of the atmospheric boundary layer height during different atmospheric conditions: A comparison on reliability of several methods applied to lidar measurements. Int. J. Remote Sens. 2017, 38, 3203-3218. [CrossRef]

44. Welton, E.J.; Campbell, J.R.; Spinhirne, J.D.; Scott, V.S. Global Monitoring of Clouds and Aerosols Using a Network of Micro-Pulse Lidar Systems. Proc. SPIE 2000, 4153, 151-158.

45. He, Q.S.; Mao, J.T.; Chen, J.Y.; Hu, Y.Y. Observational and modeling studies of urban atmospheric boundary-layer height and its evolution mechanisms. Atmos. Environ. 2006, 40, 1064-1077. [CrossRef]

46. Campbell, J.R.; Hlavka, D.L.; Spinhirne, J.D.; Turner, D.D.; Flynn, C.J. Operational cloud boundary detection and analysis from micropulse lidar data. In Proceedings of the Eighth ARM Science Team Meeting, Tucson, AZ, USA, 23-27 March 1988.

47. Perrone, M.R.; Romano, S. Relationship between the planetary boundary layer height and the particle scattering coefficient at the surface. Atmos. Res. 2018, 213, 57-69. [CrossRef]

48. Sicard, M.; Perez, C.; Comeren, A.; Baldasano, J.M.; Rocadenbosch, F. Determination of the mixing layer height from regular lidar measurements in the Barcelona area. In Proceedings of the Remote Sensing of Clouds and the Atmosphere VIII, International Society for Optics and Photonics, Barcelona, Spain, 8-12 September 2004.

49. Sugimoto, N.; Nishizawa, T.; Shimizu, A.; Matsui, I.; Jin, Y. Characterization of aerosols in east asia with the asian dust and aerosol lidar observation network (ad-net). Proc. SPIE Int. Soc. Opt. Eng. 2014, 9262. [CrossRef]

50. Leventidou, E.; Zanis, P.; Balis, D.; Giannakaki, E.; Pytharoulis, I.; Amiridis, V. Factors affecting the comparisons of planetary boundary layer height retrievals from calipso, ecmwf and radiosondes over thessaloniki, greece. Atmos. Environ. 2013, 74, 360-366. [CrossRef]

51. Emeis, S.; Schäfer, K.; Münkel, C. Surface-based remote sensing of the mixing-layer height-A review. Meteorol. Z. 2008, 17, 621-630. [CrossRef]

52. Xiang, Y.; Ye, Q.; Liu, J.; Zhang, T.; Fan, G.; Zhou, P.; Lü, L.; Liu, Y. Retrieve of Planetary Boundary Layer Height Based on Image Edge Detection. Chin. J. Lasers 2019, 43, 0110002-1-0110002-8.

53. Jain, A.K. Data Clustering: 50 Years Beyond K-Means; Springer: Berlin/Heidelberg, Germany, 2008.

54. Bruine, M.D.; Apituley, A.; Donovan, D.P.; Baltink, H.K. Pathfinder: Applying graph theory for consistent tracking of daytime mixed layer height with backscatter lidar. Atmos. Meas. Tech. 2017, 10, 1-26. [CrossRef]

55. Li, H.; Yang, Y.; Hu, X.M.; Huang, Z.; Wang, G.; Zhang, B.; Zhang, T. Evaluation of retrieval methods of daytime convective boundary layer height based on Lidar data. J. Geophys. Res.-Atmos. 2017, 122, 4578-4593. [CrossRef]

56. Dang, R.; Yang, Y.; Li, H.; Hu, X.-M.; Wang, Z.; Huang, Z.; Zhou, T.; Zhang, T. Atmosphere Boundary Layer Height (ABLH) Determination under Multiple-Layer Conditions Using Micro-Pulse Lidar. Remote Sens. 2019, 11, 263. [CrossRef]

57. Xie, H.; Zhou, T.; Fu, Q.; Huang, J.; Huang, Z.; Bi, J.; Shi, J.; Zhang, B.; Ge, J. Automated detection of cloud and aerosol features with SACOL micro-pulse lidar in northwest China. Opt. Express 2017, 25, 30732-30753. [CrossRef]

58. Zhou, T.; Hailing, X.; Jianrong, B.; Zhongwei, H.; Jianping, H.; Jinsen, S.; Beidou, Z.; Wu, Z. Lidar Measurements of Dust Aerosols during Three Field Campaigns in 2010, 2011 and 2012 over Northwestern China. Atmosphere 2018, 9, 173. [CrossRef]

59. Measures, R.M. Laser remote sensing:fundamentals and applications. Eos Trans. Am. Geophys. Union 1984, 66, 686 .

60. Welton, E.J.; Campbell, J.R. Micropulse Lidar Signals: Uncertainty Analysis. J. Atmos. Ocean. Technol. 2002, 19, 2089-2094. [CrossRef]

61. Campbell, J.R.; Hlavka, D.L.; Welton, E.J.; Flynn, C.J.; Turner, D.D.; Spinhirne, J.D. Full-time, eye-safe cloud and aerosol lidar observation at atmospheric radiation measurement program sites: Instruments and data processing. J. Atmos. Ocean. Technol. 2002, 19, 431-442. [CrossRef]

62. Kotthaus, S.; O'Connor, E.; Münkel, C.; Charlton-Perez, C.; Grimmond, C.S.B. Recommendations for processing atmospheric attenuated backscatter profiles from Vaisala CL31 ceilometers. Atmos. Meas. Tech. 2016, 9, 1-32. [CrossRef] 
63. Melfi, S.H.; Spinhirne, J.D.; Chou, S.H.; Palm, S.P. Lidar Observations of Vertically Organized Convection in the Planetary Boundary Layer over the Ocean. J. Appl. Meteorol. Climatol. 1985. [CrossRef]

64. Münkel, C.; Eresmaa, N.; Räsänen, J.; Karppinen, A. Retrieval of mixing height and dust concentration with lidar ceilometer. Bound.-Layer Meteorol. 2007, 124, 117-128. [CrossRef]

65. Hooper, W.P.; Eloranta, E.W. Lidar Measurements of Wind in the Planetary Boundary Layer: The Method, Accuracy and Results from Joint Measurements with Radiosonde and Kytoon. J. Appl. Meteorol. 1986, 25, 990-1001. [CrossRef]

66. Boers, R.; Eloranta, E.W.; Coulter, R.L. Lidar Observations of Mixed Layer Dynamics: Tests of Parameterized Entrainment Models of Mixed Layer Growth Rate. J. Appl. Meteorol. 1984, 23, 247-266. [CrossRef]

67. Nelson, E.; Stull, R.; Eloranta, E.A. A Prognostic Relationship for Entrainment Zone Thickness. J. Appl. Meteorol. 1989, 28, 885-903. [CrossRef]

68. Joffre, S.M.; Kangas, M.; Heikinheimo, M.; Kitaigorodskii, S.A. Variability of the Stable and Unstable Atmospheric Boundary-Layer Height and Its Scales over a Boreal Forest. Bound.-Layer Meteorol. 2001, 99, 429-450. [CrossRef]

69. Flamant, C.; Pelon, J.; Flamant, P.H.; Durand, P. Lidar determination of the entrainment zone thickness at the top of the unstable marine boundary layer. Bound.-Layer Meteorol. 1997, 83, 248-284. [CrossRef]

70. Quan, J.; Gao, Y.; Zhang, Q.; Tie, X.; Cao, J.; Han, S.; Meng, J.; Chen, P.; Zhao, D. Evolution of planetary boundary layer under different weather conditions, and its impact on aerosol concentrations. Particuology 2013, 11, 34-40. [CrossRef]

71. Dupont, E.; Pelon, J.; Flamant, C. Study of the moist Convective Boundary Layer structure by backscattering lidar. Bound.-Layer Meteorol. 1994, 69, 1-25. [CrossRef]

72. Strawbridge, K.B.; Snyder, B.J. Planetary boundary layer height determination during Pacific 2001 using the advantage of a scanning lidar instrument. Atmos. Environ. 2004, 38, 5861-5871. [CrossRef]

73. Boers, R.; Spinhirne, J.D.; Hart, W.D. Lidar observations of the fine-scale variability of marine stratocumulus clouds. J. Appl. Meteorol. 1988, 27, 797-810. [CrossRef]

74. Frioud, M.; Mitev, V.; Matthey, R.; Häberli, C.H.; Richner, H.; Werner, R.; Vogt, S. Elevated aerosol stratification above the Rhine Valley under strong anticyclonic conditions. Atmos. Environ. 2003, 37, 1785-1797. [CrossRef]

75. Wang, L.; Xie, C.B.; Han, Y.; Liu, D.; Wei, H.L. Comparison of retrieval methods of planetary boundary layer height from lidar data. J. Atmos. Environ. Opt. 2012, 07, 241-247.

76. Hayden, K.L.; Anlauf, K.G.; Hoff, R.M.; Strapp, J.W.; Bottenheim, J.W.; Wiebe, H.A.; Froude, F.; Martin, J.; Steyn, D.; McKendry, I.G. The vertical chemical and meteorological structure of the boundary layer in the Lower Fraser Valley during Pacific ‘93. Atmos. Environ. 1997, 31, 2089-2105. [CrossRef]

77. Tsaknakis, G.; Papayannis, A.; Kokkalis, P.; Amiridis, V.; Kambezidis, H.D.; Mamouri, R.E.; Georgoussis, G.; Avdikos, G. Inter-comparison of lidar and ceilometer retrievals for aerosol and Planetary Boundary Layer profiling over Athens, Greece. Atmos. Meas. Tech. Discuss 2011, 4, 73-99. [CrossRef]

78. Menut, L.; Flamant, C.; Pelon, J.; Flamant, P.H. Urban boundary-layer height determination from lidar measurements over the Paris area. Appl. Opt. 1999, 38, 945-954. [CrossRef]

79. Senff, C.; Bösenberg, J.; Peters, G.; Schaberl, T. Remote Sesing of Turbulent Ozone Fluxes and the Ozone Budget in the Convective Boundary Layer with DIAL and Radar-RASS: A Case Study. Atmos. Phys. 1996, 69, 161-176.

80. Martucci, G.; Matthey, R.; Mitev, V.; Richner, H. Comparison between Backscatter Lidar and Radiosonde Measurements of the Diurnal and Nocturnal Stratification in the Lower Troposphere. J. Atmos. Ocean. Technol. 2006, 24, 1158-1164. [CrossRef]

81. Yang, T.; Wang, Z.; Zhang, W.; Gbaguidi, A.; Sugimoto, N.; Wang, X.; Matsui, I.; Sun, Y. Technical note: Boundary layer height determination from lidar for improving air pollution episode modeling: Development of new algorithm and evaluation. Atmos. Chem. Phys. 2017, 17, 6125-6225. [CrossRef]

82. Ji, X.; Liu, C.; Xie, Z.; Hu, Q.; Dong, Y.; Fan, G.; Zhang, T.; Xing, C.; Wang, Z.; Javed, Z.; et al. Comparison of mixing layer height inversion algorithms using lidar and a pollution case study in Baoding, China. J. Environ. Sci. 2018, 79, 81-90. [CrossRef] [PubMed]

83. Sicard, M.; Pérez, C.; Rocadenbosch, F.; Baldasano, J.M.; García-Vizcaino, D. Mixed-Layer Depth Determination in the Barcelona Coastal Area from Regular Lidar Measurements: Methods, Results and Limitations. Bound.-Layer Meteorol. 2006, 119, 135-157. [CrossRef] 
84. Banks, R.F.; Baldasano, J.M.; Comerón, A.; Sicard, M.; Rocadenbosch, F. Inter-comparison of lidar methods for obtaining planetary boundary-layer height from a July 2012 monitoring campaign over the Iberian Peninsula in the framework of EARLINET. In Proceedings of the Fall Meeting of the American Geophysical Union, San Francisco, CA, USA, 9-13 December 2013.

85. Steyn, D.G.; Baldi, M.; Hoff, R.M. The Detection of Mixed Layer Depth and Entrainment Zone Thickness from Lidar Backscatter Profiles. J. Atmos. Ocean. Technol. 1999, 16, 953-959. [CrossRef]

86. Eresmaa, N.; Karppinen, A.; Joffre, S.M.; Räsänen, J.; Talvitie, H. Mixing height determination by ceilometer. Atmos. Chem. Phys. Discuss. 2005, 5, 12697-12722. [CrossRef]

87. HÄGeli, P.; Steyn, D.G.; Strawbridge, K.B. Spatial and Temporal Variability of Mixed-Layer Depth and Entrainment Zone Thickness. Bound.-Layer Meteorol. 2000, 97, 47-71. [CrossRef]

88. Mok, T.M.; Rudowicz, C.Z. A lidar study of the atmospheric entrainment zone and mixed layer over Hong Kong. Atmos. Res. 2004, 69, 147-163. [CrossRef]

89. Mallat, S.; Hwang, W.L. Singularity detection and processing with wavelets. IEEE Trans. Inf. Theory 1992, 38, 617-643. [CrossRef]

90. Cohn, S.A.; Angevine, W.M. Boundary Layer Height and Entrainment Zone Thickness Measured by Lidars and Wind-Profiling Radars. J. Appl. Meteorol. Climatol. 2000, 39, 1233-1247. [CrossRef]

91. Davis, K.J.; Hagelberg, C.R.; Kiemle, C.; Lenschow, D.H.; Sullivan, P.P.; Gamage, N. An Objective Method for Deriving Atmospheric Structure from Airborne Lidar Observations. J. Atmos. Ocean. Technol. 2000, 17, 1455-1468. [CrossRef]

92. Wulfmeyer, V.; Janji, T. Twenty-Four-Hour Observations of the Marine Boundary Layer Using Shipborne NOAA High-Resolution Doppler Lidar. J. Appl. Meteorol. 2005, 44, 1723-1744. [CrossRef]

93. Brooks, I.M. Finding Boundary Layer Top: Application of Wavelet Covariance Transform to Lidar Backscatter Profiles. J. Atmos. Ocean. Technol. 2003, 20, 1092-1105. [CrossRef]

94. Haij, M.D.; Wauben, W.; Baltink, H.K. Determination of mixing layer height from ceilometer backscatter profiles. Proc. SPIE Int. Soc. Opt. Eng. 2006, 6362. [CrossRef]

95. Gan, C.M.; Wu, Y.; Madhavan, B.L.; Gross, B.; Moshary, F. Application of active optical sensors to probe the vertical structure of the urban boundary layer and assess anomalies in air quality model PM2.5 forecasts. Atmos. Environ. 2011, 45, 6613-6621. [CrossRef]

96. Dang, R.J.; Li, H.; Liu, Z.; Yang, Y. Statistical analysis of relationship between daytime lidar-derived planetary boundary layer height and relevant atmospheric variables in the semiarid region in northwest China. Adv. Meteorol. 2016, 2016, 1-13. [CrossRef]

97. Gamage, N.; Hagelberg, C. Detection and Analysis of Microfronts and Associated Coherent Events Using Localized Transforms. J. Atmos. Sci. 1993, 50, 750-756. [CrossRef]

98. Collineau, S.; Brunet, Y. Detection of turbulent coherent motions in a forest canopy part I: Wavelet analysis. Bound.-Layer Meteorol. 1993, 65, 357-379. [CrossRef]

99. Morille, Y.; Haeffelin, M.; Drobinski, P.; Pelon, J. STRAT: An Automated Algorithm to Retrieve the Vertical Structure of the Atmosphere from Single-Channel Lidar Data. J. Atmos. Ocean. Technol. 2007, 24, 761-775. [CrossRef]

100. Singh, U.N.; Pappalardo, G.; Gregori, d.A.M. Comparison between two algorithms based on different wavelets to obtain the Planetary Boundary Layer height. In Proceedings of the SPIE Remote Sensing, Amsterdam, The Netherlands, 22-25 September 2014; Volume 9246.

101. Li, H.; Ma, Y.; Yang, Y. Study on Retrieval of Boundary Layer Height Using Wavelet Transformation Method Basd on Lidar Data. J. Arid Meteorol. 2015, 33, 78-88.

102. Chen, W.; Novak, M.D.; Black, T.A.; Lee, X. Coherent eddies and temperature structure functions for three contrasting surfaces. Part I: Ramp model with finite microfront time. Bound.-Layer Meteorol. 1997, 84, 99-124. [CrossRef]

103. Coulter, R.L. Comparison of three methods for measuring mixing-layer height. J. Appl. Meteorol. 1979, 18, 1495-1499. [CrossRef]

104. Sawyer, V.; Li, Z. Detection, variations and intercomparison of the planetary boundary layer depth from radiosonde, lidar and infrared spectrometer. Atmos. Environ. 2013, 79, 518-528. [CrossRef]

105. Pal, S.; Behrendt, A.; Wulfmeyer, V. Elastic-backscatter-lidar-based characterization of the convective boundary layer and investigation of related statistics. Ann. Geophys. 2010, 28, 825-847. [CrossRef] 
106. Mao, F.; Gong, W.; Song, S.; Zhu, Z. Determination of the boundary layer top from lidar backscatter profiles using a Haar wavelet method over Wuhan, China. Opt. Laser Technol. 2013, 49, 343-349. [CrossRef]

107. Piironen, A.K.; Eloranta, E.W. Convective boundary layer mean depths and cloud geometrical properties obtained from volume imaging lidar data. J. Geophys. Res. Atmos. 1995, 100, 25569-25576. [CrossRef]

108. Lammert, A.; Bösenberg, J. Determination of the convective boundary-layer height with laser remote sensing. Bound.-Layer Meteorol. 2006, 119, 159-170. [CrossRef]

109. Träumner, K.; Kottmeier, C.; Corsmeier, U.; Wieser, A. Convective Boundary-Layer Entrainment: Short Review and Progress using Doppler Lidar. Bound.-Layer Meteorol. 2011, 141, 369-391.

110. Huang, M.; Gao, Z.; Miao, S.; Chen, F.; Lemone, M.A.; Li, J.; Hu, F.; Wang, L. Estimate of Boundary-Layer Depth Over Beijing, China, Using Doppler Lidar Data During SURF-2015. Bound.-Layer Meteorol. 2017, 162, 503-522. [CrossRef]

111. Luo, T.; Yuan, R.; Wang, Z. Lidar-based remote sensing of atmospheric boundary layer height over land and ocean. Atmos. Meas. Tech. 2014, 7, 173-182. [CrossRef]

112. He, Q.; Li, C.; Mao, J.; Lau, K.H.; Chu, D.A. Analysis of aerosol vertical distribution and variability in Hong Kong. J. Geophys. Res. Atmos. 2008, 113. [CrossRef]

113. Schween, J.H.; Hirsikko, A.; Löhnert, U.; Crewell, S. Mixing-layer height retrieval with ceilometer and Doppler lidar: From case studies to long-term assessment. Atmos. Meas. Tech. 2014, 7, 4275-4319. [CrossRef]

114. Schäfer, K.; Emeis, S.; Junkermann, W.; Münkel, C. Evaluation of mixing layer height monitoring by ceilometer with SODAR and microlight aircraft measurements. Proc. SPIE 2005, 5979, 442-452.

115. Stachlewska, I.S.; Migacz, S.; Szkop, A.; Zielińska, A.J.; Swaczyna, P.L. Ceilometer observations of the boundary layer over Warsaw, Poland. Acta Geophys. 2012, 60, 1386-1412. [CrossRef]

116. Haeffelin, M.; Angelini, F.; Morille, Y.; Martucci, G.; Frey, S.; Gobbi, G.P.; Lolli, S.; O’Dowd, C.D.; Sauvage, L.; Xueref-Rémy, I.; et al. Evaluation of Mixing-Height Retrievals from Automatic Profiling Lidars and Ceilometers in View of Future Integrated Networks in Europe. Bound.-Layer Meteorol. 2012, 143, 49-75. [CrossRef]

117. Canny, J.F. Computational Approach to Edge Detection. IEEE Trans. Pattern Anal. Mach. Intell. 1986, 6, 679-698. [CrossRef]

118. Lammert, A. Untersuchung der Turbulenten Grenzschicht mit Laserfernerkundung. Ph.D. Thesis, Universität Hamburg, Hamburg, Germany. 2004.

119. Martucci, G.; Matthey, R.; Mitev, V.; Richner, H. Frequency of Boundary-Layer-Top Fluctuations in Convective and Stable Conditions Using Laser Remote Sensing. Bound.-Layer Meteorol. 2010, 135, 313-331. [CrossRef]

120. Martucci, G.; Milroy, C.; Dowd, O.; Colin, D. Detection of Cloud-Base Height Using Jenoptik CHM15K and Vaisala CL31 Ceilometers. J. Atmos. Ocean. Technol. 2010, 27, 305. [CrossRef]

121. Baars, H.; Ansmann, A.; Engelmann, R.; Althausen, D. Continuous monitoring of the boundary-layer top with lidar. Atmos. Chem. Phys. 2008, 8, 7281-7296. [CrossRef]

122. Sobel, I.; Feldman, G. A $3 \times 3$ isotropic gradient operator for image processing, presented at a talk at the Stanford Artificial Project. In Pattern Classification and Scene Analysis; Duda, R., Hart, P., Eds.; John Wiley \& Sons: Hoboken, NJ, USA, 1968; pp. 271-272.

123. Wang, C.; Shi, H.; Jin, L.; Chen, H.; Wen, H. Measuring boundary-layer height under clear and cloudy conditions using three instruments. Particuology 2016, 28, 15-21. [CrossRef]

124. Yang, D.; Li, C.; Lau, K.H.; Li, Y. Long-term measurement of daytime atmospheric mixing layer height over Hong Kong. J. Geophys. Res. Atmos. 2013, 118, 2422-2433. [CrossRef]

125. Su, T.; Li, J.; Li, C.; Xiang, P.; Lau, K.H.; Guo, J.; Yang, D.; Miao, Y. An intercomparison of long-term planetary boundary layer heights retrieved from CALIPSO, ground-based lidar and radiosonde measurements over Hong Kong. J. Geophys. Res. Atmos. 2017, 122, 3929-3943. [CrossRef]

126. Li, H.; Yang, Y.; Hu, X.-M.; Huang, Z.W.; Wang, G.Y.; Zhang, B.D. Application of Convective Condensation Level Limiter in Convective Boundary Layer Height Retrieval Based on Lidar Data. Atmosphere 2017, 8, 79. [CrossRef]

127. Toledo, D.; Córdoba-Jabonero, C.; Gil-Ojeda, M. Cluster Analysis: A new approach applied to Lidar measurements for Atmospheric Boundary Layer height estimation. J. Atmos. Ocean. Technol. 2014, 31, 422-436. [CrossRef] 
128. Banks, R.F.; Tiana-Alsina, J.; Baldasano, J.M.; Rocadenbosch, F. Retrieval of boundary layer height from lidar using extended Kalman filter approach, classic methods, and backtrajectory cluster analysis. Proc. SPIE 2014, 9242, 1-16.

129. Lange, D.; Tiana-Alsina, J.; Saeed, U.; Tomás, S.; Rocadenbosch, F. Atmospheric Boundary Layer Height Monitoring Using a Kalman Filter and Backscatter Lidar Returns. IEEE Trans. Geosci. Remote Sens. 2013, 52, 4717-4728. [CrossRef]

130. Tomás, S.; Rocadenbosch, F.; Sicard, M. Atmospheric boundary-layer height estimation by adaptive Kalman filtering of lidar data. Proc. SPIE 2010, 7827, 239.

131. Rocadenbosch, F.; Vázquez, G.; Comerón, A. Adaptive filter solution for processing lidar returns: Optical parameter estimation. Appl. Opt. 1998, 37, 7019-7034. [CrossRef]

132. Rocadenbosch, F.; Soriano, C.; Adolfo, C.; Baldasano, J.M. Lidar inversion of atmospheric backscatter and extinction-to-backscatter ratios by use of a Kalman filter. Appl. Opt. 1999, 38, 3175-3189. [CrossRef]

133. Gregori, D.A.M.; Luis, G.R.J.; Antonio, J.B.A.; Antonio, J.B.O.; Pablo, O.A.; Roberto, R.; Esteban, A.B.V.; Landulfo, E.; Lucas, A.A. Study of the planetary boundary layer by microwave radiometer, elastic lidar and Doppler lidar estimations in Southern Iberian Peninsula. Atmos. Res. 2018, 213, 185-195.

134. Alexiou, D.; Kokkalis, P.; Papayannis, A.; Rocadenbosch, F.; Argyrouli, A.; Tsaknakis, G.; Tzanis, C.G. Planetary boundary layer height variability over athens, greece, based on the synergy of raman lidar and radiosonde data: Application of the kalman filter and other techniques (2011-2016). EPJ Web Conf. 2018, 176. [CrossRef]

135. Lange, D.; Rocadenbosch, F.; Tiana-Alsina, J.; Frasier, S. Atmospheric Boundary Layer Height Estimation Using a Kalman Filter and a Frequency modulated Continuous-wave Radar. IEEE Trans. 2015, 53, 3338-3349. [CrossRef]

136. Sugimoto, N.; Matsui, I.; Shimizu, A. Observation of dust and anthropogenic aerosol plumes in the Northwest Pacific with a two-wavelength polarization lidar on board the research vessel Mirai. Geophys. Res. Lett. 2002, 29, 7-1-7-4. [CrossRef]

137. Burton, S.P.; Hair, J.W.; Ferrare, R.A.; Hostetler, C.A.; Kahnert, M.; Vaughan, M.A.; Cook, A.L.; Harper, D.B.; Berkoff, T.; Seaman, S.T.; et al. Aerosol Classification from High Spectral Resolution Lidar Measurements; AGU Fall Meeting; AGU Fall Meeting Abstracts; AGU: Washington, DC, USA, 2015.

138. Liu, B.; Ma, Y.; Gong, W.; Yang, J.; Zhang, M. Two-wavelength Lidar inversion algorithm for determining planetary boundary layer height. J. Quant. Spectrosc. Radiat. Transf. 2018, 206, 117-124. [CrossRef]

139. Liu, B.M.; Ma, Y.Y.; Gong, W.; Zhang, M.; Yang, J. Improved Two-wavelength Lidar algorithm for Retrieving Atmospheric Boundary Layer Height. J. Quant. Spectrosc. Radiat. Transf. 2018, 224, 55-61. [CrossRef]

140. Bravo-Aranda, J.A.; Gregori, M.D.A.; Navas-Guzmán, F.; Granados-Muñoz, M.J.; Guerrero-Rascado, J.L.; Pozo-Vázquez, D.; Arbizu-Barrena, C.; Reyes, F.J.O.; Mallet, M.; Arboledas, L.A. A new methodology for PBL height estimations based on lidar depolarization measurements: Analysis and comparison against MWR and WRF model-based results. Atmos. Chem. 2017, 17, 6839-6851. [CrossRef]

(C) 2019 by the authors. Licensee MDPI, Basel, Switzerland. This article is an open access article distributed under the terms and conditions of the Creative Commons Attribution (CC BY) license (http://creativecommons.org/licenses/by/4.0/). 